\title{
Does Violent Crime Deter Physical Activity?
}

\author{
Katharina Janke ${ }^{\mathrm{a}}$, Carol Propper ${ }^{\mathrm{b}}$, and Michael A. Shields ${ }^{\mathrm{c}}$ \\ a University of Bristol, United Kingdom \\ ${ }^{\mathrm{b} U n i v e r s i t y ~ o f ~ B r i s t o l ~ a n d ~ I m p e r i a l ~ C o l l e g e, ~ L o n d o n, ~ U n i t e d ~ K i n g d o m ~}$ \\ cMonash University, Melbourne, Australia
}

October 31, 2014

\begin{abstract}
We investigate an underexplored externality of crime: the impact of violent crime on physical activity through individuals' participation in walking, for many adults the only regular physical activity. We use a sample of nearly 1 million people in 323 small areas in England between 2005 and 2011, matched to quarterly crime data at small area level. Within area variation identifies the causal effect of local violent crime on walking and a difference-in-difference analysis of two highprofile crimes corroborates our results. We find a substantive deterrent effect of violent crime on walking that translates into a drop in overall physical activity.
\end{abstract}

JEL Classification: I12, I18, R23

Keywords: Violent Crime, Walking, Physical Activity, Externality 


\section{Introduction}

It has been long recognised that crime has important externalities. One key concern is the impact of crime on neighbourhood quality and community. Established negative externalities on neighbourhood include flight to the suburbs (Cullen and Levitt 1999, Ellen and O'Regan 2010), declining property values (Gibbons 2004), a reduction in the creation of new retail and personal service businesses (Greenbaum and Tita 2004) and geographical sorting of local businesses (Rosenthal and Ross 2010). In this paper we investigate an hitherto underexplored externality: the impact of violent crime on individuals' participation in physical activity through their participation in the most common form of physical activity undertaken in their local area, walking.

This is a substantive issue for three main reasons. Firstly, although homicide rates are low in Western Europe, other serious violent offences, including those that result in injury, are not uncommon. In our country of study, England, violent crime with injury accounts for $10 \%$ of all recorded crime. Moreover, individuals tend to overestimate their chances of being a victim of violent crime. ${ }^{1}$ Individuals get information about crime from the media (Duffy et al. 2008) and media reporting has been shown to be highly selective, focusing on the most serious examples of crime. In contrast, the lower level property offences that make up the majority of recorded crime are given sparse attention (Greer 2007). ${ }^{2}$

Secondly, walking is an important form of exercise. It is free and available to everyone regardless of age, gender or income. For many adults walking is the only form of regular exercise. In our sample, $30 \%$ of respondents report no exercise other than walking while $20 \%$ of respondents report no exercise at all. The importance of at least moderate physical activity as a determinant of good health has been well established (U.S. Department of Health and Human Services 1996, World Health Organization 2002). Despite this, walking has been decreasing in many industrialised countries ${ }^{3}$ and this fall has been linked to the rise in obesity and obesity related diseases (Bassett et al. 2008, Lindström 2008), many of which impose substantial costs on individuals and health care systems.

\footnotetext{
${ }^{1}$ In a survey $15 \%$ of respondents said that they were 'very likely' or 'fairly likely' to be a victim of violent crime in the next 12 months, while according to the same survey only $3 \%$ of adults reported being actual victims of violent crime in the last 12 months (Home Office 2010).

${ }^{2}$ Studying local print media in Australia for the period 2001 to 2006, Cornaglia and Leigh (2011) find 600 media mentions of violent crime in local papers each year, compared to 230 mentions of property crime.

${ }^{3}$ In the UK, the average distance walked, per person per year, has fallen from 255 miles in 1975/76 to 201 miles in 2006 (NICE 2012).
} 
Thirdly, walking has important externalities. For example, individuals who walk in their local neighbourhood contribute to a sense of community (du Toit et al. 2007). A shift from walking to driving as a mode of transport increases carbon emissions, noise levels, air pollution and congestion (Sinnett et al. 2011). Besides the environmental costs, costly motorised transport as as substitute for free walking imposes an economic cost on the individual. Pedestrians are also an important factor in ensuring a vibrant local economy (Sinnett et al. 2011). ${ }^{4}$

Concerns about personal safety are commonly cited in research as a barrier to local walking (Foster and Giles-Corti 2008). But the literature to date has not found clear results for the relationship between crime and walking or physical engagement in the community. A review concluded that this was partly as a result of non-causal design and small data sets (Foster and Giles-Corti 2008).

We seek to overcome these problems by using a sample of nearly 1 million people in 323 small areas (local authorities) in England over six years matched to quarterly police recorded crime data at the small area level. England is a good test bed for two reasons. First, crime statistics are available at small area level, with the six-year period covered by our data providing considerable variation in crime rates across time and space and second, the English government collects information on physical activity on a consistent basis for a very large sample of adults every year, giving many observations at small area level. These repeated cross-section data provide an identification strategy in which we can control for area effects, area specific time trends, national time effects and a number of potential time-varying confounders such as unemployment at the area level and local weather. ${ }^{5}$

To complement this analysis, we use a difference-in-difference approach to examine the impact on walking of two high-profile crimes that caused a crime shock at the local level. In December 2010, Joanna Yeates went missing in Bristol. Her body was discovered eight days later on Christmas Day. The hunt for her killer received extensive media coverage, with police issuing warnings to women to avoid walking home alone after dark while her killer remained at large. On 22 January 2011 Vincent Tabak was charged with her murder. In March 2009, Claudia Lawrence went missing in York. Her body was never found but one line of inquiry was that she was abducted while walking to work early in the morning. Her disappearence also received extensive media coverage.

\footnotetext{
${ }^{4} \mathrm{~A}$ survey of customers on a local high street found that shoppers who had walked there visited more shops than those arriving by car (Sustrans 2006).

${ }^{5}$ For the relationship between weather and crime see, for example, Cohn (1990) and Jacob et al. (2007).
} 
Our analysis shows that individuals' concerns regarding their personal safety positively co-move with recorded violent crime. An increase in recorded crime within a local area is statistically significantly associated with increased worry about being mugged or attacked and individuals equate increases in police recorded crime with their own assessment of crime changes. These results support our modelling assumption that increases in recorded violent crime in a local area induce greater concerns about personal safety, which in turn lead to individuals changing their physical activity behaviour.

Our main results show that increased violent crime in the local area leads to a statistically significant reduction in walking and this drop translates into a drop in overall physical activity. Most of the drop is in transport walking, which is more likely to take place in the locality in which an individual lives than leisure walking. Thus, crime hurts both local particpation and the total amount of exercise taken by individuals. Our analysis of the impact of the murder of Joanna Yeates and the disappearance of Claudia Lawrence supports our main findings, also showing a fall in walking and overall physical activity following a local crime shock.

The adverse effect of an increase in local area violent crime from the $25^{\text {th }}$ to the $75^{\text {th }}$ percentile is equivalent in size to the effect of a $7^{\circ} \mathrm{C}$ fall in average minimum temperature and back-of-the-envelope calculations suggests that reducing violent crime to the $25^{\text {th }}$ percentile of our sample distribution could generate direct benefits of $£ 4.1$ million annually, even before any calculation of possible positive externalities from reductions in traffic congestion and pollution.

Our analysis contributes to the literature on the wider detrimental impacts of crime on non-victims. Our paper is closest to a small number of papers that have examined the effect of crime risk on individuals' daily activities. Kling et al. (2001) report that parents living in areas of high crime tried to keep their children indoors to avoid them becoming victims of violence. Hamermesh (1999) demonstrates that victimisation risk affects working time patterns in the USA. Braakmann (2012) shows that individuals in Mexico respond to victimisation from crime by taking measures to protect themselves, such as changing their mode of transport or carrying a weapon.

We also link to studies which have found an impact of crime on health, both physical and mental. Sundquist et al. (2006) report an association between area-level violent crime and coronary heart disease and Messer et al. (2006) find an association with preterm birth and low birth weight. For Australia, Cornaglia et al. (2014) find strong effects of both recorded violent crime and media reports of violent crime on reductions in mental wellbeing. For Britain, Dustmann and Fasani (2013) identify a substantive effect of both property crime and violent crime on mental distress. Finally, a number 
of papers estimate subjective wellbeing and behavioural impacts of high profile acts of violence, including the September 11 terrorist attacks (Metcalfe et al. 2011) and the London bombings in 2005 (Rubin et al. 2005, Dustmann and Fasani 2013).

The paper is structured as follows. In Section 2 we describe our data and provide an analysis of the relationship between changes in police recorded violent crime and individuals' concerns about their own personal safety. Section 3 presents our main empirical identification strategy and Section 4 discusses our main estimates and robustness tests. Section 5 describes our analysis of the impact of the murder of Joanna Yeates and the disappearance of Claudia Lawrence. In Section 6 we estimate the social cost of less walking due to crime. Section 7 concludes.

\section{Data}

\subsection{The sample and our physical activity measures}

Our data are from the Active People Survey (APS), a cross-sectional survey of adults in England designed explicitly to measure levels of participation in sport and active recreation at the local level. The survey contains detailed measures of physical activity undertaken in the last four weeks prior to interview as well as a wide range of individual and household level demographic and socio-economic characteristics. Importantly, interviews are spread evenly across the 12 months of each survey period, and run from mid-October one year to mid-October the next year. Further details are in Appendix A.

We use five waves of these data, covering the period October 2005 to October 2011. ${ }^{6}$ The first four waves of the survey cover all 354 local authorities in England. Local authorities are the primary unit of local government, responsible for provision of a range of services, including education, public housing, social services and leisure and recreation services. ${ }^{7}$ The number of local authorities was reduced to 326 in 2009 following local government reorganisation and we match the 354 authorities into their 326 counterparts (most local authorities did not change), giving us a total pooled sample of 1,104,155 individuals aged 16 and above residing in 326 areas.

We drop a number of cases to obtain our working sample. We omit three local authorities: the Isles of Scilly and the City of London because of their very small populations, and the London Borough of Westminster because of its very high crime

\footnotetext{
${ }^{6}$ The survey did not run October 2006 to October 2007.

${ }^{7}$ Local authorities vary in population but most have populations of 60,000 to 300,000 .
} 
rate, which is due to the difference between the resident and the daytime population, a high proportion of whom are tourists. We exclude respondents who indicated that they are unable to walk and respondents aged 75 or over as their walking ability might be low. After eliminating respondents with missing values for our outcome variables, we are left with a sample of 964,318 adults residing in 323 local authorities over a period of 22 quarters.

Our main outcome variable is the time spent walking at a steady average pace or faster continuously for at least 30 minutes in the last four weeks. This measure is derived from a series of questions respondents are asked about the number of days they walked, whether this was for 30 minutes continuously or not, and the pace of their walking. For more detail about these questions see Appendix A. We only count walking at a steady average pace or above, since walking at a slower pace will not count towards the UK government's physical activity target, which is based on the health benefits derived from exercise. ${ }^{8}$ We also split the walking variable into leisure and transport walking. Respondents are asked on how many of their walking days were they walking for the purpose of health or recreation (and not just to get from place to place). We define the number of days given in response to this question as leisure walking days and construct a measure of transport walking days by subtracting leisure walking days from all walking days. ${ }^{9}$ As respondents might interpret "for the purpose of health or recreation" in a way that counts transport walking as leisure walking, potentially causing measurement error in both the leisure walking and the transport walking variable, our focus is on all walking.

We also construct a measure of the total time spent doing at least moderate intensity physical activity in the last four weeks to examine whether the impact of crime is to decrease all activity or to substitute indoor or group activities for riskier walking. This measure is derived from the record of the length of time respondents undertook any activity from a list of over 400 other types of sport and recreational physical activity over the last four weeks. The most common activities are swimming, going to the gym, football, aerobics and racket sports. Individuals report on how many days in the last four weeks they undertook each type of activity as well as how long they usually do each activity. We exclude any activity that, according to a list provided by Sport England, is only light intensity (for example bowls, darts and snooker). ${ }^{10}$ For each at

\footnotetext{
${ }^{8}$ As the reported number of walking days refers to walks lasting at least 30 minutes, we approximate the time spent walking in the last four weeks by multiplying the number of walking days by 30 minutes.

${ }^{9}$ Again, we approximate the time spent walking for the purpose of leisure and the time spent walking for the purpose of transport by multiplying the number of walking days by 30 minutes.

${ }^{10}$ There are some activities that can potentially be undertaken at light, moderate or vigorous in-
} 


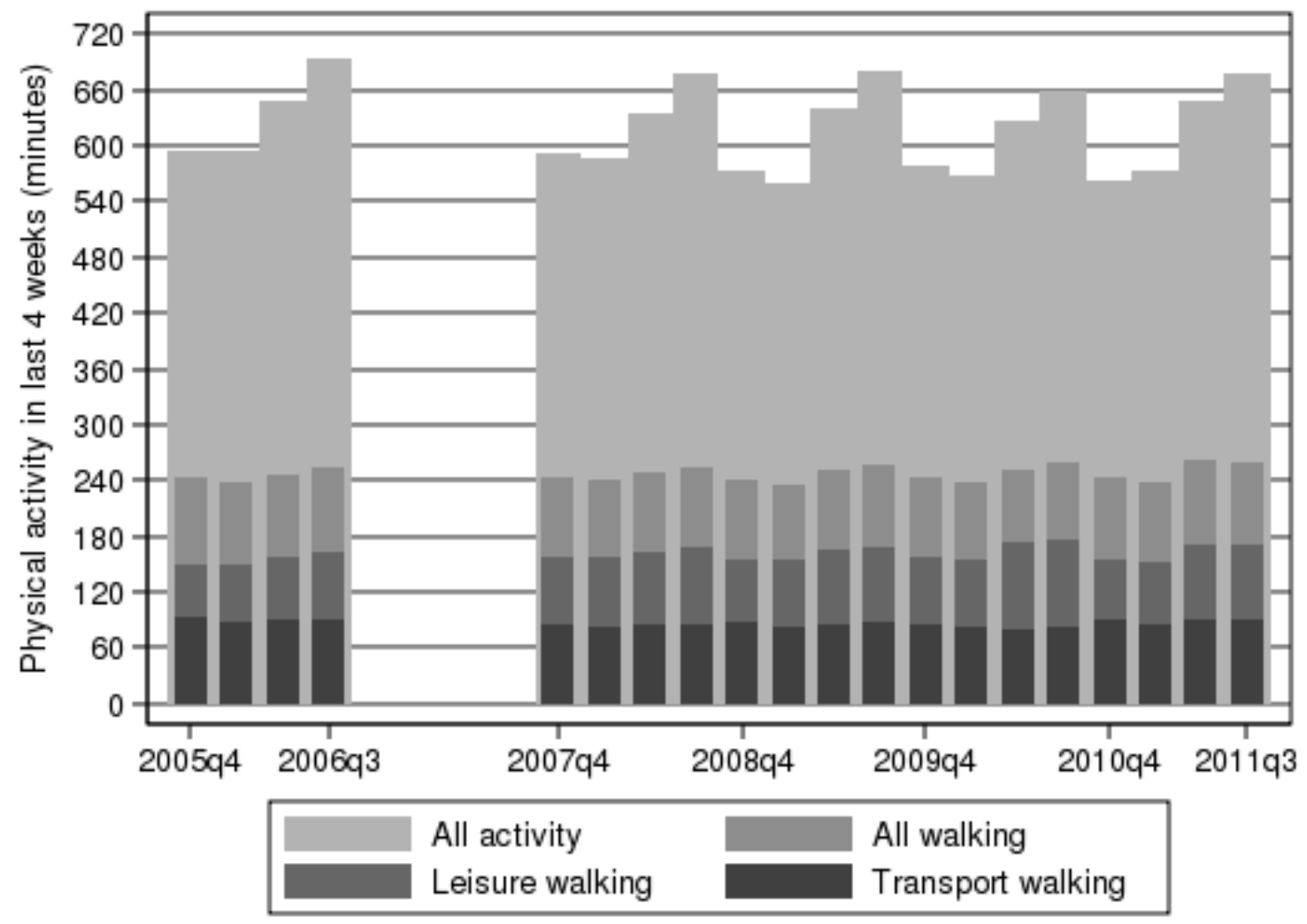

Figure 1: Quarterly means of walking days in last 4 weeks

least moderate intensity activity, we multiply the number of days by the usual duration and sum over all activities. We add this sum to our measures of time spent walking and cycling (which is recorded in the same way as the walking variable $)^{11}$ to obtain a measure of the total time spent doing at least moderate intensity physical activity in the last four weeks.

The top section of Table 1 shows a sample mean of 622 minutes of at least moderate intensity physical activity i.e. the average individual achieves the recommended 150 minutes of moderate intensity activity per week (150 minutes $\times 4$ weeks $=600$ minutes). However, the median of 360 minutes suggests that half of all individuals do at most 90 minutes of physical activity. $20 \%$ of the sample do nothing. At the mean, 247 minutes are spent walking in the last four weeks. This value is $40 \%$ of the sample mean for all physical activity and shows that walking is an important, and for some indivudals tensity, such as table tennis, pilates or trampolining. We include such an activity if the respondent says "yes" to the question "During the last four weeks, was the effort you put into ... usually enough to raise your breathing rate?", as it indicates at least moderate intensity.

${ }^{11}$ For cycling, the number of minutes is not recorded, only the number of days on which the respondent cycled continuously for at least 30 minutes, so we multiply the number of cycling days by 30 minutes. 
the only, form of exercise. Figure 1 shows the time trend (quarterly means) of all physical activity and of walking during the sample period. It is clear that walking is an important component of all activity and that there is no obvious time trend but a strong seasonal pattern in all physical activity and walking. Activity in the UK is lowest in the winter months (the last and first quarters of the year) and highest in the summer (quarter 3). On the other hand, there is little seasonal pattern in transport walking; the seasonality is driven by leisure walking.

Table 1: Descriptive statistics

\begin{tabular}{|c|c|c|c|c|c|}
\hline Variable & Mean & St. dev. & $25^{\text {th }}$ perc. & Median & $75^{\text {th }}$ perc. \\
\hline \multicolumn{6}{|l|}{ Outcome variables $(\mathrm{N}=964,318)$} \\
\hline \multicolumn{6}{|c|}{ Time spent walking in last 4 weeks (minutes) } \\
\hline All & 247.1 & 293.9 & 0 & 120 & 420 \\
\hline Transport & 87.0 & 190.2 & 0 & 0 & 60 \\
\hline Leisure & 160.1 & 250.7 & 0 & 30 & 210 \\
\hline All physical activity (minutes) & 621.9 & 895.0 & 60 & 360 & 840 \\
\hline \multicolumn{6}{|l|}{$\begin{array}{l}\text { Local authority variables } \\
(\mathrm{N}=7,093, \mathrm{n}=323, \overline{\mathrm{t}}=21.96)\end{array}$} \\
\hline \multicolumn{6}{|l|}{ Number of offences per 1,000 population } \\
\hline $\begin{array}{r}\text { Violent crime with injury } \\
\text { Between } \\
\text { Within }\end{array}$ & 7.32 & $\begin{array}{l}3.3 \\
3.0 \\
1.4\end{array}$ & 4.8 & 6.8 & 9.3 \\
\hline Remaining offences & 71.81 & 27.6 & 51.5 & 65.7 & 86.9 \\
\hline Between & & 25.5 & & & \\
\hline Within & & 10.4 & & & \\
\hline Unemployment rate & 5.8 & 2.3 & 4.1 & 5.4 & 7.1 \\
\hline Between & & 1.9 & & & \\
\hline Within & & 1.3 & & & \\
\hline Police officers per 100,000 population & 165.9 & 59.5 & 129.3 & 149.0 & 181.0 \\
\hline Between & & 56.1 & & & \\
\hline Within & & 20.1 & & & \\
\hline PCSOs per 100,000 population & 23.4 & 11.3 & 17.9 & 22.3 & 26.4 \\
\hline Between & & 9.0 & & & \\
\hline Within & & 6.9 & & & \\
\hline \multicolumn{6}{|l|}{$\begin{array}{l}\text { Weather variables } \\
(\mathrm{N}=389,105, \mathrm{n}=323, \overline{\mathrm{t}}=1,204.7)\end{array}$} \\
\hline Rainfall (mm) & 2.0 & 1.3 & 1.1 & 1.8 & 2.7 \\
\hline Maximum temperature $\left({ }^{\circ} \mathrm{C}\right)$ & 14.1 & 5.8 & 9.0 & 14.6 & 19.0 \\
\hline Minimum temperature $\left({ }^{\circ} \mathrm{C}\right)$ & 6.5 & 4.5 & 2.5 & 6.5 & 10.5 \\
\hline
\end{tabular}

PCSOs $=$ Police Community Support Officers 


\subsection{Police recorded crime}

Our crime measures are derived from quarterly police recorded crime data at local authority level. The data contain the number of offences notifiable to the Home Office in 10 major categories (violence against the person, sexual offences, robbery, burglary, offences against vehicles, other theft offences, fraud and forgery, criminal damage, drug offences, other miscellaneous offences). We create quarterly rates per 1,000 population using National Statistics mid-year population estimates. We then assign to each APS survey respondent the sum of the quarterly rates in the four quarters preceding the interview quarter - essentially the rolling annual crime rate. As most people experience crime only indirectly, updating of beliefs about crime prevalence is likely to take longer than one quarter. Additionally, changes in the quarterly crime rate may be due to chance rather than systematic changes in crime prevalence, increasing measurement error. Summing over the previous four quarters cancels out random errors. In Appendix B.1 we examine the robustness of our results to alternative definitions of the crime measurement period.

We focus on violent crime with injury offences. ${ }^{12}$ Descriptive statistics in Table 1 show a sample average of 7.3 violent crime with injury offences per 1,000 population. ${ }^{13}$ The most common offences in this category are "actual bodily harm (ABH) and other injury", which accounts for $89 \%$ of offences, and "inflicting grievous bodily harm (GBH)", which accounts for around $10 \%$ of offences. The remaining $1 \%$ of violent crime with injury offences include murder, attempted murder, causing death by dangerous driving and racially or religiously aggravated ABH or other injury (Home Office 2011). For most people the main information source on crime is the local and national media and as already noted, violent crime dominates media reporting on crime (Williams and Dickinson 1993, Chermak 1994, Cornaglia and Leigh 2011). Therefore, it seems likely that individuals focus on this type of crime when evaluating the security aspects of their walking decision.

\footnotetext{
${ }^{12}$ The most common violent crime without injury offences are "harassment, public fear, alarm or distress", punishable with a fine, and "assault without injury", punishable with a fine or imprisonment not exceeding 6 months, each of them accounting for around $40 \%$ of offences in this category (Home Office 2011). The other two major types of personal crime - sexual offences and robbery - together account for only $3 \%$ of all police recorded offences while property crime (burglary, offences against vehicles, other theft offences, fraud and forgery, criminal damage) accounts for $70 \%$ of police recorded offences.

${ }^{13} \mathrm{~A}$ common criticism leveled at police recorded crime is that it does not reflect the true extent of crime as it contains only crimes that have been discovered, reported to the police and then recorded by the police (Coleman and Moynihan 1996). However, for the crimes that we expect to impact on individuals' perceived probability of becoming a victim of crime while walking - violence against the person with injury - police recorded crime provide reasonable coverage (Coleman and Moynihan 1996).
} 

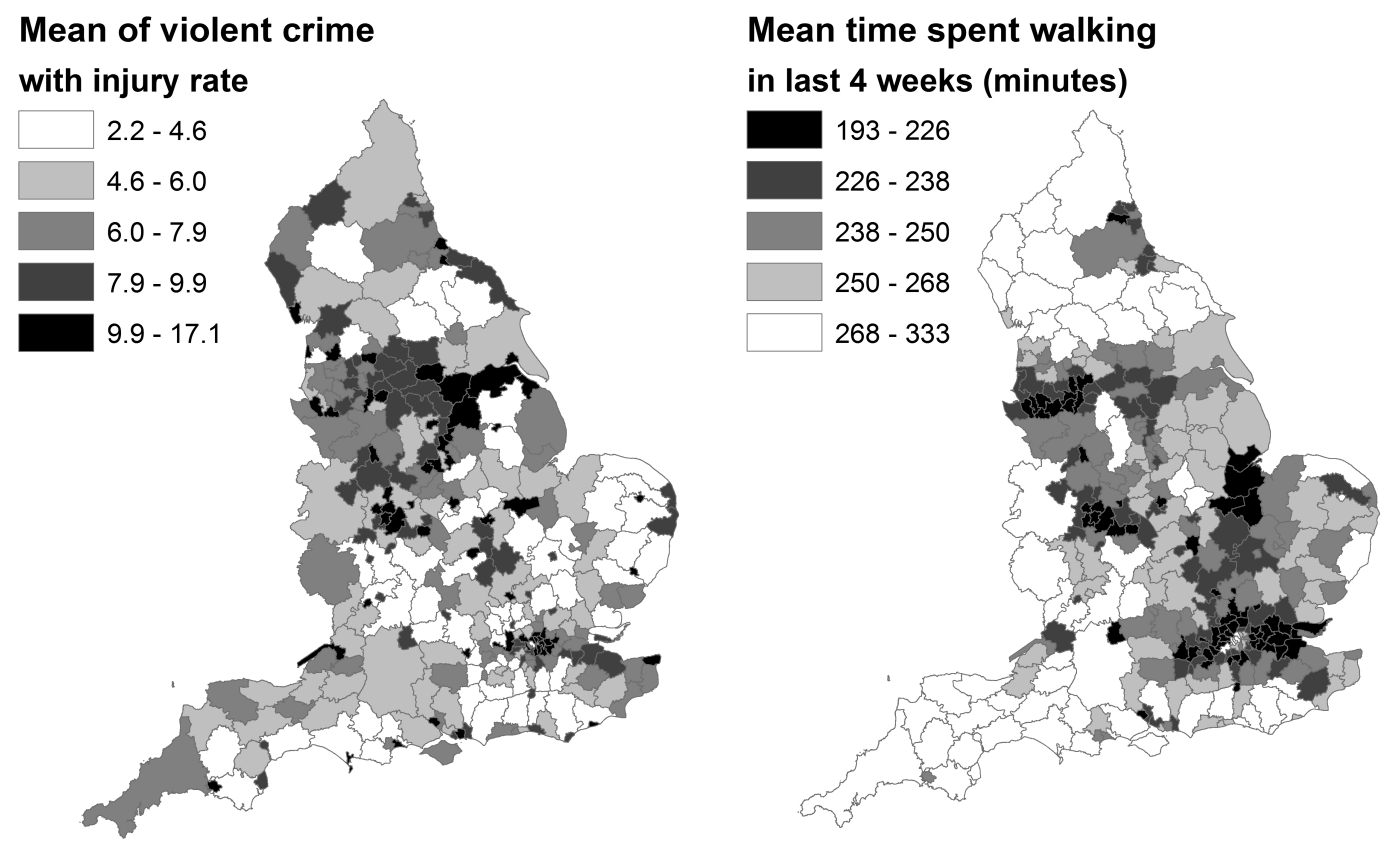

Figure 2: Local authority means of violent crime with injury rate and time spent walking in last 4 weeks

We use all other crime (total crime minus violent crime with injury) as a control to capture changes in recording practices, technological change in crime fighting and changes in policing practices at local authority level that might confound the relationship between violent crime and walking. ${ }^{14}$

Figure 2 maps the local authority means of the violent crime with injury rate in the preceding four quarters and the time spent walking in the last four weeks. The left hand side of Figure 2 maps crime, with areas with least crime in white and most crime in black. The map shows that crime is higher in urban areas (the darker areas in the central parts of the country) but also in several local authorities along the south coast of England. The right hand side map shows walking, with areas with more walking in white and least walking in black. It shows that walking is higher in rural areas (the

\footnotetext{
${ }^{14}$ For example, the Police Reform Act 2002 introduced Police Community Support Officers (PCSOs), who have limited powers and whose main role is to provide a visible and reassuring presence on the streets. Employment of PCSOs varies across police force areas. The Metropolitan Police Service (responsible for law enforcement in Greater London) recruited the first PCSOs in September 2002 and still has the highest contingent of PCSOs (Johnston 2006). In Section 4.2 we examine the robustness of our results to including controls for the number of Police Officers and the number of PCSOs.
} 
extreme North of England, the South West peninsular and the rural local authorities on the Welsh border). The maps suggest that areas with higher crime rates have lower walking rates (visually mainly in the northern half of England).

\subsection{Individual and household level controls}

The APS collects information about a wide range of individual and household-level characteristics. When selecting controls we wished to control for individuals' time and income constraints. As proxies for time endowment we use dummy variables indicating the respondent's employment status (working full-time, working part-time, unemployed less than 12 months, unemployed more than 12 months, retired, not working because of children, not working because of disability, student, other) and family structure (single adult, children aged 0 to 4, 5 to 10, 11 to 15). Dummies for household income in six bands and an indicator for living in public (social rented) housing serve as proxies for the respondent's budget.

Education is likely to affect the demand for walking, either through its relationship with time preference or through its effect on the efficiency of the health production process (Grossman 2006). We therefore control for the respondent's highest educational attainment as well as gender and ethnicity. Car ownership is likely to be another important determinant of walking, so we include a dummy indicating whether a car is available for use by the respondent or other members of the household. We also control for respondents' age (in five ten-year bands beginning at age 16) and for a dummy variable indicating whether the respondent had a limiting long-standing illness or disability. Finally, we control for the day of the week the interview took place.

Where there are missing values for the covariates we include indicator variables to control for this non-response. We add a separate dummy variable indicating missingness due to certain questions not being asked in APS5. Descriptive statistics for these controls are in Appendix Table A-2.

\subsection{Area-level controls}

To capture local economic conditions that might be correlated with local crime and potentially make the local environment more or less attractive for walking, we use unemployment rates for the four quarters preceding the interview. We also control for weather conditions. Using data from the UK Meteorological Office we calculate the inverse-distance weighted mean of daily maximum temperature, daily minimum temperature and daily precipitation measured at the weather stations within a $30 \mathrm{~km}$ 
radius (20 km for precipitation) around the local authority's centroid over the four week period preceding the interview. Descriptive statistics for these variables are at the bottom of Table 1.

\subsection{The relationship between recorded violent crime and con- cerns about personal safety in the British Crime Survey}

The number of police recorded violent offences with injury can affect individuals' walking decisions only if it affects their perceived probability of becoming a victim of crime in their local area. To test this key assumption, we examine the relationship between police recorded crime and survey data on perception of, and worry about, crime. As the APS does not contain any information on respondents' concerns about personal safety in their local area, we analyse the relationship between police recorded violent crime and perception of and worry about crime using data from the British Crime Survey (BCS).

The BCS is a household survey conducted annually of around 45,000 respondents. Respondents are asked:

- "How much would you say the crime rate here has changed since two years ago? In this area, would you say there is more crime or less crime?" with answers on a five point scale running from "A lot more crime" to "A lot less crime". We construct a binary variable that takes the value 1 if the respondent answers "a lot more crime" or "a little more crime" and 0 otherwise.

- "How worried are you about being mugged and robbed?" and "How worried are you about being physically attacked by strangers?" with answers on a four point scale from "very worried" to "not at all worried". We construct a binary variable that takes the value 1 if the respondent answers very worried or fairly worried and 0 otherwise.

We use the 2005-06, 2006-07 and 2007-08 waves of the BCS as these identify in which of the 38 police force areas in England the respondent resides and assign to each respondent the violent crime with injury rate in the police force area of residence over the four quarters preceding their interview quarter. We estimate linear probability models of the relationship between our recorded violent crime with injury variable and perception of and worry about crime, conditioning on a set of individual-level demographic and socio-economic controls similar to those in the APS (discussed in Section 2.3; means of BCS controls are in Table A-3). 
Table 2: Linear probability models of relationship between police force area rate of violent crime with injury and perception of crime

\begin{tabular}{lccc}
\hline \hline & Crime up & Worry mugged & Worry attack \\
\hline Without area effects & 0.016 & $0.140^{* * *}$ & $0.113^{* * *}$ \\
& $(0.030)$ & $(0.037)$ & $(0.032)$ \\
With area effects & $0.092^{* * *}$ & $0.044^{* * *}$ & $0.047^{* *}$ \\
& $(0.029)$ & $(0.013)$ & $(0.018)$ \\
\hline Mean of dependent variable & 0.40 & 0.35 & 0.35 \\
Areas & 38 & 38 & 38 \\
Observations & 91,290 & 113,753 & 113,750 \\
\hline \hline
\end{tabular}

Coefficient on log violent crime with injury shown, with robust standard errors in brackets, clustered by police force area. All coefficients from separate regressions. All regressions include individual-level controls for gender, age, ethnicity, highest educational attainment, employment status, an indicator for a limiting long-standing illness or disability, family structure, household income, an indicator for living in social rented housing and an indicator for car in household. *Significant at $10 \%$, $* *$ significant at $5 \%, * * *$ significant at $1 \%$

Table 2 presents the coefficients on the (log of the) violent crime rate. Results in the first row are without police force area effects, while those in the second row include police force area effects. The first column shows that cross-sectionally there is no association between the violent crime rate and a perceived increase in crime, but within police force area there is a strong association between violent crime and the perception of crime. Respondents do not, therefore, confuse living in a high crime area with a rise in crime in their area. A rise in reported crime in the local area from the $25^{\text {th }}$ to the $75^{\text {th }}$ percentile increases the probability of reporting an increase in crime by 3 percentage points $(0.35 \times 0.092=0.032)$. Both variables measuring worry about crime are correlated cross-sectionally and within police force areas with recorded crime. These results provide empirical support for our assumption that the perceived probability of becoming a victim of crime depends on the number of police recorded offences in the local area. 


\section{Empirical strategy}

\subsection{Estimation equation}

To identify the causal effect of violent crime on walking we exploit quarterly within area variation in our data. We estimate:

$$
\text { Physical activity }_{i a t}=\beta \sum_{j=1}^{4} \text { crime }_{a(t-j)}+\boldsymbol{X}_{a t}^{\prime}+\boldsymbol{Z}_{i a t}^{\prime} \boldsymbol{\theta}+\lambda_{t}+\alpha_{a}+\delta_{a} t+\varepsilon_{i a t}
$$

Our main measure of physical activity is the time (in minutes) individual $i$ in local authority $a$ interviewed in time period $t$ has spent walking at a steady average pace or faster continuously for at least 30 minutes in the last four weeks. We also analyse walking separated into leisure and transport walking and the total time spent doing at least moderate intensity physical activity in the last four weeks (walking + cycling + other activities). Time period $t$ is a calendar quarter. The explanatory variable of interest is $\sum_{j=1}^{4} c_{r i m e} e_{a(t-j)}$, police recorded crime in local authority $a$ in the previous four quarters.

A full set of time effects, $\lambda_{t}$, provides nonparametric control for trends in crime and walking that are national in scope. Local authority effects $\alpha_{a}$ control for non-time varying unobserved differences between local authorities. Local authority-specific time trends $\delta_{a} t$ parametrically control for deviations from national time effects, capturing changes to the local infrastructure or policing that might confound the association between local crime rates and walking. $\boldsymbol{X}_{a t}^{\prime}$ and $\boldsymbol{Z}_{i a t}^{\prime}$ are vectors of local authority and individual-specific controls, respectively, as discussed in Sections 2.3 and 2.4. We estimate robust standard errors that allow for clustering at the local authority level.

\subsection{Test of our empirical strategy}

As deviations in the violent crime rate from the quarterly national average, the local authority average and the local authority specific trend are unlikely to be correlated with omitted factors, our design should recover the causal effect of violent crime on walking. We examine this assumption here. Essentially, Equation 1 is a generalised model for grouped individual and aggregate level data that incorporates standard difference-indifference models (see Hansen (2007)). Formally, Equation 1 would be the same as a simple difference-in-difference estimator if there were only two periods (first difference) and two areas (second difference). In our implementation we have 22 quarters and 323 local authorities, which increases our ability to identify the causal effect of crime 


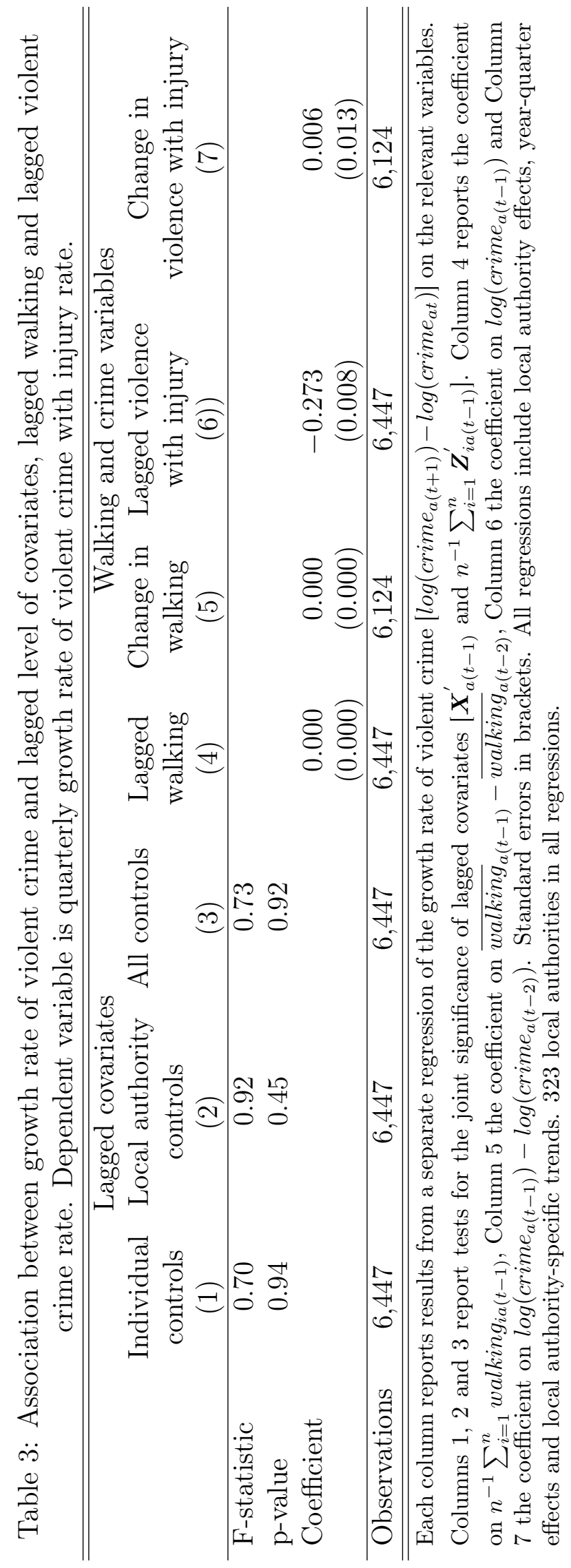


on walking. To test whether the difference-in-difference assumptions are satisfied, we examine the relationship between the observed baseline conditions and subsequent changes in the violent crime rate. Any association between crime growth rates and baseline conditions after controlling for local authority effects, year-quarter effects and local authority-specific time trends may indicate that local authorities that differ in terms of crime growth also differ in terms of time-variant unobserved factors, which would violate the assumptions underlying our causal design.

Table 3, Columns 1 to 3, presents regressions of crime growth between $t+1$ and $t$ on blocks of the individual and local authority covariates, separately and jointly, in $t-1$. As crime growth is measured at local authority level, we aggregate the individuallevel data to local authority-quarter level. The results show no significant association between the baseline conditions (separately or jointly) and crime growth. In Columns 4 and 5 we check for any association between future crime growth and levels and changes in past local authority-quarter means of time spent walking. We see that neither are statistically significantly associated with subsequent crime growth. In Column 6 we examine the relationship between crime growth and the past level of crime. The coefficient on the lagged level of crime is negative and statistically significantly different from zero, suggesting that in local authorities with higher baseline levels of crime the crime rate dropped more sharply. However, Column 7 shows that lagged crime growth is not associated with subsequent crime growth. In sum, these tests provide support for our identification strategy.

\section{Results}

\subsection{Main results}

We begin by estimating the simple correlation between the local authority rate of violent crime with injury and the time spent walking at a steady average pace or faster continuously for at least 30 minutes in the last four weeks (essentially what is seen by comparing the maps in Figure 2). Column 1 in Table 4 presents the coefficient on the log of the violent crime rate in an OLS regression with no controls. It shows a statistically significant negative association.

Columns 2 to 6 present results from regressions that sequentially add individuallevel controls, local authority effects, time effects, local authority controls and local authority-specific trends. Adding individual-level controls reduces the coefficient on the crime rate by $20 \%$. Additionally controlling for local authority effects increases the 
Table 4: Estimates of effect of local authority rate of violent crime with injury on time spent walking at steady average pace or faster continuously for at least 30 minutes in last four weeks.

\begin{tabular}{lcccccc}
\hline \hline & 1 & 2 & 3 & 4 & 5 & 6 \\
\hline Log(violent crime & $-20.4^{* * *}$ & $-16.0^{* * *}$ & $-22.4^{* * *}$ & $-9.4^{* * *}$ & $-11.2^{* * *}$ & $-14.8^{* * *}$ \\
with injury) & $(2.6)$ & $(2.4)$ & $(1.8)$ & $(3.2)$ & $(3.7)$ & $(5.1)$ \\
$\log ($ other crime) & & & & & 8.4 & 8.7 \\
& & & & & $(5.3)$ & $(8.4)$ \\
$\log ($ unemployment) & & & & & $9.7^{* * *}$ & 2.1 \\
& & & & & $(3.2)$ & $(4.0)$ \\
Rainfall & & & & & $-1.2^{* * *}$ & $-1.2^{* * *}$ \\
& & & & & $(0.3)$ & $(0.3)$ \\
Maximum temperature & & & & & $0.7^{* *}$ & $0.6^{*}$ \\
& & & & & $(0.3)$ & $(0.3)$ \\
Minimum temperature & & & & & $1.3^{* * *}$ & $1.4^{* * *}$ \\
& & & & & $(0.4)$ & $(0.4)$ \\
Individual controls & No & Yes & Yes & Yes & Yes & Yes \\
Local author. effects & No & No & Yes & Yes & Yes & Yes \\
Time effects & No & No & No & Yes & Yes & Yes \\
LA-specific trends & No & No & No & No & No & Yes \\
\hline R-squared & 0.001 & 0.027 & 0.032 & 0.033 & 0.033 & 0.033 \\
\hline \hline
\end{tabular}

Robust standard errors in brackets, clustered by local authority. Individual-level controls are gender, age, ethnicity, highest educational attainment, employment status, an indicator for a limiting longstanding illness or disability, family structure, household income, an indicator for living in social rented housing and an indicator for car in household. 964,318 observations in 323 local authorities in all regressions. ${ }^{*}$ Significant at $10 \%,{ }^{* *}$ significant at $5 \%,{ }^{* * *}$ significant at $1 \%$ 
coefficient by $40 \%$. Adding time effects halves the coefficient and subsequently adding local authority controls increases the coefficient by $20 \%$. Adding local authority-specific trends in Column 6 - the specification in Equation 1 - increases the coefficient on the crime rate by $30 \%$ to 14.8 . The effect of the controls is as follows. Neither the local authority unemployment rate or the all other crime rate is statistically significant, suggesting that our time and local authority effects control for unobserved factors that may be associated with both overall crime levels and unemployment. The weather controls are statistically significant. Rainfall reduces walking while temperature rises (in both the lowest and the highest temperatures) increase walking. Both of these accord with intuition: walking in the rain and the cold is less enjoyable.

To gauge the economic significance of our results, we calculate the predicted change in the time spent walking as a result of a fall in the crime rate from the $75^{\text {th }}$ to the $25^{\text {th }}$ percentile of the sample distribution. This drop is equal to a fall of 0.66 points in the $\log$ crime rate, so a fall of this size leads to 10 minutes increase in walking $(0.66 \times$ $14.8=9.77)$, which is equivalent to a $4 \%$ increase at the sample mean of 247 minutes. In comparison, an increase in the average minimum temperature from the $25^{\text {th }}$ to the $75^{\text {th }}$ percentile results in a predicted increase in walking of 11 minutes. For the average maximum temperature the predicted increase is 6 minutes. Therefore, the impact of violent crime on the time spent walking is comparable to the impact of temperature in England.

Next, we investigate the effect of crime separately for transport walking and leisure walking and also examine the effect on the total time spent doing at least moderate intensity physical activity. Intuitively, transport walking could be more affected than leisure walking, because individuals have less discretion over where and when to walk if the aim is to get from place to place, making the local crime rate more relevant. The top row of Table 5 presents the results. The first column reproduces our baseline estimate from the final column of Table 4 . The crime coefficient in the transport walking regression is statistically significant at the $1 \%$ level and $70 \%$ larger than the statistically insignificant crime coefficient in the leisure walking regression. The predicted increase in transport walking as a result of a drop in the violent crime rate from the $75^{\text {th }}$ to the $25^{\text {th }}$ percentile is 6 minutes, a $7 \%$ increase at the mean of 87 minutes.

The last column of Table 5 shows that a reduction in walking due to a crime increase leads to a drop in total time spent doing at least moderate physical activity in the last four weeks. Using the $25^{\text {th }}$ to $75^{\text {th }}$ percentile contrast, the predicted effect of an increase in crime is a 15 minutes drop in total physical activity, a $2.4 \%$ decrease 
Table 5: Estimates of effect of local authority rate of violent crime with injury on time spent doing physical activity by type

\begin{tabular}{lcccc}
\hline \hline & All walking & Transport walking & Leisure walking & All activity \\
\hline Log(violent crime & $-14.8^{* * *}$ & $-9.4^{* * *}$ & -5.4 & $-22.3^{*}$ \\
with injury) & $(5.1)$ & $(3.0)$ & $(4.3)$ & $(12.8)$ \\
\hline \hline
\end{tabular}

Coefficient on log violent crime with injury shown, with robust standard errors in brackets, clustered by local authority. 964,318 observations in 323 local authorities in all regressions. All regressions include local authority effects, year-quarter effects and local authority-specific trends as well as controls for all other crime, unemployment, rainfall, daily maximimum and minimum temperature and individual-level controls for gender, age, ethnicity, highest educational attainment, employment status, an indicator for a limiting long-standing illness or disability, family structure, household income, an indicator for living in social rented housing and an indicator for car in household. *Significant at $10 \%,{ }^{*}$ significant at $5 \%,{ }^{* * *}$ significant at $1 \%$

at the mean of 622 minutes. ${ }^{15}$ As discussed above, the predicted effect on all walking is a 10 minutes drop. The predicted drop in total physical activity therefore exceeds the predicted drop in walking. The reason could be that other outdoor activities such as running or cycling are also considered risky. But importantly, the fall suggests that individuals do not substitute other types of physical activity for walking. This overall fall is supported by Audrey et al. (2014), who used accelerometers to obtain an objective measure of physical activity and found that over a week total physical activity was lower in employees who travelled to work by car than those who walked.

We also examine whether the effect of crime is heterogeneous across gender by adding interactions of the area-level controls and the individual-level controls with the male dummy variable. For walking, the coefficient on $\log$ (violent crime with injury) is -19.6 (s.e. 5.1) and the coefficient on the interaction with male is 11.1 (s.e. 3.0) which suggests that males respond less than females. For all physical activity, the crime coefficient is -34.6 (s.e. (13.3) and the interaction coefficient is 30.2 (10.5), indicating that women reduce total physical activity in response to an increase in crime. One reason for women's stronger response is that walking is a more important form of exercise for women. For women $63 \%$ percent of the proportion of time spent doing moderate intensity physical activity is due to walking; for men the comparable proportion is $51 \%$. Thus, a drop in walking due to an increase in crime translates into a larger drop in overall physical activity for women. This result also fits with studies that show that women perceive crime to be higher than do men (Hipp 2010) and with

\footnotetext{
${ }^{15}$ The coefficient for all activity is less well defined than the crime coefficient in the walking regression. However, a robustness test extending the crime measurement period from the previous four quarters to the previous six quarters in Appendix B.1 estimates a crime coefficient statistically significant at the $5 \%$ level of $-42.0($ s.e. $=16.5)$. This result suggests that in the longer term an increase in crime from the $25^{\text {th }}$ to $75^{\text {th }}$ percentile reduces all physical activity by 28 minutes, a $4.5 \%$ decrease at the mean.
} 
Braakmann (2012) who finds that in Mexico women respond differently from men to victimisation from crime. Specifically, women were more likely to change their mode of transport and to adopt other avoidance strategies while men were more likely to carry a weapon and go out more.

\subsection{Robustness tests}

Here we assess the robustness of our results to controlling for police resources and provide evidence that our findings are not driven by residential sorting. In Appendix $\mathrm{B}$ we demonstrate the robustness of our results to changes in the crime measurement period and present results from a nonlinear model that accounts for the lumpiness in the distribution of our main outcome variables.

Whilst our econometric strategy controls for unobserved time-invariant differences between local authorities and local authority specific time trends, it is possible that time-varying differences between local authorities drive the results. One potential source of time-varying differences are differential changes in police resources across local authorities. For example, an increase in high visibility policing might reduce crime and simultaneously reassure local residents, thereby encouraging them to walk more. Hence, the coefficient on the crime variable could incorrectly reflect the effect of increased police presence on walking. On the other hand, police resources could be endogenous with respect to crime.

To investigate these issues, we re-estimate our main model with additional controls for police resources. The Home Office publishes full-time equivalents of police officers and Police Community Support Officers (PCSOs) for the 38 Police Forces in England. The count on 31 March of each year also provides separate numbers for the Basic Command Units of a Police Force and the Police Force's central services. The 323 local authorities in our sample are covered by 159 Basic Command Units. ${ }^{16}$ For most urban areas the Basic Command Unit boundaries coincide with the local authority boundaries. In rural areas, a Basic Command Unit tends to cover several local authorities. We match the officer counts for the Basic Command Units, which exlude officers working in central services and therefore less likely to be a local presence, to the local authorities in our sample.

The results in Table 6 show that our finding of a deterrent effect of violent crime on walking and total time spent doing physical activity is robust to controlling for police

\footnotetext{
${ }^{16}$ Some of the Basic Command Units in our data are different from the real Basic Command Units, because we had to aggregate some units to achieve consistency across our six-year sample period over which restructuring of local policing took place.
} 
Table 6: Estimates of the effect of local authority rate of violent crime with injury on time spent doing physical activity in last four weeks with additional controls for police resources

\begin{tabular}{lcc}
\hline \hline & Walking & All activity \\
\hline Log(violent crime with injury) & $-14.2^{* * *}$ & $-21.8^{*}$ \\
& $(5.0)$ & $(12.8)$ \\
$\log ($ other crime) & 6.9 & 4.6 \\
& $(8.4)$ & $(22.7)$ \\
$\log ($ police officers) & $-11.6^{*}$ & -13.4 \\
& $(6.6)$ & $(18.6)$ \\
$\log ($ PCSOs) & $5.5^{* *}$ & 9.4 \\
& $(2.2)$ & $(6.2)$ \\
\hline R-squared & 0.033 & 0.077 \\
\hline \hline
\end{tabular}

Robust standard errors in brackets, clustered by local authority. All regressions include local authority effects, year-quarter effects and local authority-specific trends as well as controls for unemployment, rainfall, daily maximimum and minimum temperature and individual-level controls for gender, age, ethnicity, highest educational attainment, employment status, an indicator for a limiting long-standing illness or disability, family structure, household income, an indicator for living in social rented housing and an indicator for car in household. 964,318 observations in 323 local authorities in all regressions. *Significant at $10 \%,{ }^{* *}$ significant at $5 \%,{ }^{* * *}$ significant at $1 \%$

resources. The negative coefficients on $\log$ (police officers) suggest that police officers are endogenous. Presumably, an increase in police officer numbers signals an increase in crime, so the coefficient on police officers captures part of the deterrent effect of crime.

Another concern might be that our results do not capture changes in behaviour but sorting effects. In particular, individuals who like walking might move out of local authorities with increasing crime levels into local authorities with lower crime rates, generating a negative association between violent crime and walking. However, in Appendix B.1 we find a negative effect of crime on walking even when limiting the crime measurement period to the previous quarter only, a time frame that seems too short for relocation decisions.

To examine the potential sorting bias directly, we analyse population flows from internal migration data published by the Office for National Statistics. The data are a local authority's outflows and inflows over a yearly period ending in June. We match these data to the local authority's crime rate in the previous yearly period ending in June. For example, migration data for the period July 2005 to June 2006 is matched to crime data for the period July 2004 to June 2005. We use migration data for the years 
Table 7: Association between local authority violent crime and population flows

\begin{tabular}{lcc}
\hline \hline & Outflow & Inflow \\
\hline Without local authority effects & -214.4 & -253.0 \\
& $(188.3)$ & $(164.9)$ \\
With local authority effects & $-45.9^{* * *}$ & 7.8 \\
& $(16.8)$ & $(16.6)$ \\
\hline Mean of dependent variable & 7,914 & 7,883 \\
Areas & 323 & 323 \\
Observations & 1,938 & 1,938 \\
\hline \hline
\end{tabular}

Coefficient on violent crime with injury shown, with robust standard errors in brackets, clustered by local authority. All coefficients from separate regressions. All regressions control for all other crime and year effects. ${ }^{*}$ Significant at $10 \%,{ }^{*}$ significant at $5 \%, * * *$ significant at $1 \%$

ending in June 2006 to 2011 and control for all other crime as well as year effects. ${ }^{17}$ Table 7 presents the coefficients on the violent crime rate. The results in the first row are with local authority effects. The negative coefficients suggest that local authorities with higher violent crime rates experience smaller population flows. Results in the second row include local authority effects, indicating that a within local authority increase in crime is associated with a statistically signficant drop in outflows and a very small and statistically insignificant rise in inflows. Therefore, there is no evidence of movements from local authorities with increasing crime rates to local authorities with decreasing crime rates.

\section{Evidence from two high-profile crimes}

To further corroborate our results for the impact of shocks in local crime on walking we exploit two high-profile crimes. These are the murder of Joanna Yeates in Bristol in December 2010 and the disappearance of Claudia Lawrence in York in March 2009. Both events received extensive coverage in the British media. ${ }^{18}$.

Yeates was 25-year-old landscape architect who went missing on 17 December 2010 in Bristol after an evening out with colleagues. Her body was discovered on 25 December 2010 about 3 miles from her home. On 30 December 2010, Yeates' landlord, who lived in the same building, was arrested on suspicion of her murder but released on bail on 1 January 2011 (Morris 2011a). On 2 January 2011, Bristol police issued a fresh warning to women to avoid walking home alone after dark as Yeates' killer remained at

\footnotetext{
${ }^{17} \mathrm{As}$ in our main analyses, we exclude the City of London, Westminster and the Isles of Scilly.

${ }^{18}$ Both victims where white, middle class women and therefore "ideal victims" from the media's perspective (Greer 2007)
} 
large (Morris 2011b). On 20 January 2011, police arrested 32-year-old Vincent Tabak, who lived with his girlfriend in the flat next door to Yeates. On 22 January 2011, Tabak was charged with the murder of Yeates (Morris 2011a).

Lawrence was a 35-year-old chef at the University of York. She was last seen nearing her home in Heworth, York, on the afternoon of 18 March 2009 as she returned from work. That evening she spoke to her parents by telephone and sent a text message to a friend. She failed to arrive at work for her early morning shift the following day and has not been seen since. On 20 March 2009 her father reported her missing after entering her house and finding everything as if she had left it to go to work: "Her bike was in the kitchen because it was a nice day and she was walking into work". Her mother spoke publicly of her fear that Lawrence had been taken on her walk to work, after her parents' attempts to persuade her to use a car failed. On 25 March 2009 police announced that Lawrence had "probably come to some harm" (Barkham 2009).

\subsection{Estimation method}

We begin with a simple difference-in-difference estimator:

$$
\widehat{\gamma}^{D I D}=\left(\bar{Y}_{T R E A T, P O S T}-\bar{Y}_{T R E A T, P R E}\right)-\left(\bar{Y}_{C, P O S T}-\bar{Y}_{C, P R E}\right)
$$

$\bar{Y}$ is the mean of the time spent walking in the last four weeks reported by individuals in the treated local authorities after the event $\left(\bar{Y}_{T R E A T, P O S T}\right)$ and before the event $\left(\bar{Y}_{T R E A T, P R E}\right)$ and in the remaining English local authorities after the event $\left(\bar{Y}_{C, P O S T}\right)$ and before the event $\left(\bar{Y}_{C, P R E}\right)$. To implement this estimator we run the following regression:

$$
Y_{i a t}=\alpha+\beta_{1} P O S T_{t}+\beta_{2} T R E A T_{a}+\beta_{3} P O S T_{t} \cdot T R E A T_{a}+\varepsilon_{i a t}
$$

The dependent variable, $Y_{\text {iat }}$, is the time spent walking in the last four weeks reported by individual $i$ in local authority $a$ on day $t . P O S T_{t}$ is an indicator equal to 1 if individual $i$ is interviewed after the event. $T R E A T_{a}$ is an indicator equal to 1 if the respondent lives in a local authority affected by the event. The coefficient of interest is $\beta_{3}$.

One weakness of the difference-in-difference estimator is the common trend assumption. It might be violated if seasonal changes in walking differ between the treated areas and the control areas. Therefore, we additionally employ the differentially adjusted difference-in-difference estimator proposed by Bell et al. (1999), which is similar 
to a triple difference estimator. Essentially, we take another time interval over which a similar seasonal trend has occured to purge the difference-in-difference estimates from differential trends. The same seasonal changes are likely to have occured in the same time period in the year prior to the event. Hence, the differentially adjusted difference-in-difference estimator takes the form

$$
\begin{aligned}
\widehat{\gamma}^{D A D I D}= & {\left[\left(\bar{Y}_{T, P O S T, Y E A R}-\bar{Y}_{T, P R E, Y E A R}\right)-\left(\bar{Y}_{C, P O S T, Y E A R}-\bar{Y}_{C, P R E, Y E A R}\right)\right] } \\
& -\left[\left(\bar{Y}_{T, P O S T, Y E A R-1}-\bar{Y}_{T, P R E, Y E A R-1}\right)-\left(\bar{Y}_{C, P O S T, Y E A R-1}-\bar{Y}_{C, P R E, Y E A R-1}\right)\right]
\end{aligned}
$$

In practice, we run the following regression:

$$
\begin{aligned}
Y_{i a t}= & \alpha+\beta_{1} P_{S S T_{t}+\beta_{2} T R E A T_{a}+\beta_{3} Y E A R_{t}+\beta_{4} P O S T_{t} \cdot T R E A T_{a}+\beta_{5} T R E A T_{a} \cdot Y E A R_{t}} \\
& +\beta_{6} P_{T S T} \cdot Y E A R_{t}+\beta_{7} P O S T_{t} \cdot T R E A T_{a} \cdot Y E A R_{t}+\varepsilon_{i a t}
\end{aligned}
$$

$Y E A R_{t}$ is a dummy variable indicating observations in the year of the event. The coefficient of interest is $\beta_{7}$.

Table 8: Number of individuals in each group

A. Murder of Joanna Yeates

\begin{tabular}{l|rr|r} 
& Before & After & Total \\
\hline Untreated & 17,941 & 10,721 & 28,662 \\
Treated & 229 & 95 & 324 \\
\hline Total & 18,170 & 10,816 & 28,986
\end{tabular}

B. Disappearence of Claudia Lawrence

\begin{tabular}{l|rr|r} 
& Before & After & Total \\
\hline Untreated & 17,081 & 16,758 & 33,839 \\
Treated & 245 & 265 & 510 \\
\hline Total & 17,326 & 17,023 & 34,349
\end{tabular}

To analyse the impact of the murder of Joanna Yeates we define as the treatment area the local authorities of the former Avon area, i. e. the City of Bristol, South Gloucestershire, Bath \& North East Somerset and North Somerset. We define the treatment window as from 27 December 2010, i.e. the day after police confirmed the body found by two walkers on Christmas day was indeed Joanna Yeates' body, to 22 January, the day Vincent Tabak was charged with Yeates' murder. We omit individuals interviewed between 25 December 2010 and 9 January 2011, as for these respondents a maximum of only 13 days of the 28-day reporting period were affected by the crime shock. Similarly, we include individuals interviewed up to 6 February 2011, as for them 
at least 14 days of the 28-day reporting period were affected by this event. The before period is 14 November 2010 to 24 December 2010, because for individuals interviewed during that period at least 14 days of the 28-day reporting period are after the end of daylight saving time on 31 October 2010, making the before period comparable to the treatment period. Table 8 shows the number of individuals in each of the four groups for the difference-in-difference analysis.

For our analysis of the impact of the disappearance of Claudia Lawrence we define the treatment area as the city of York and the local authorities that share a border with York, i.e. Hambleton, Ryedale, East Riding of Yorkshire, Selby and Harrogate. The treatment period begins on 25 March 2009, the day police admitted Lawrence had probably come to harm. We omit individuals interviewed between 19 March 2009 and 7 April 2009 to ensure at least 14 days of the 28-day reporting period are after the crime shock. As neither a body nor a suspect have been found to date, the end of the treatment period is less clear. We include individuals interviewed up to 17 May 2009, giving us five full weeks of interviews. The control period is 9 February 2009 to 18 March 2009, providing five full weeks of interviews before the shock. The number of observations in each of the four groups for the difference-in-difference analysis are in Table 8.

\subsection{Results}

Table 9 presents the results for the crime shock caused by the murder of Joanna Yeates. The first column shows results using the difference-in-difference estimator (Equation 2) and the second column provides results for the differentially adjusted difference-indifference estimator (Equation 3).

Both the difference-in-difference estimator $(\mathrm{d}-\mathrm{i}-\mathrm{d})$ and the differentially adjusted difference-in-difference estimator suggest that the shock decreased walking by around 30 minutes, a $15 \%$ drop at the mean of 235 minutes. Both estimates are statistically significant. The effect seems to be driven by a drop in leisure walking. The two estimators give different results for all physical activity. While the $\mathrm{d}$-i-d estimate suggests that the shock reduced physical activity by 108 minutes - a $20 \%$ drop at the mean of 544 minutes - the differentially adjusted difference-in-difference estimate is positive but small and statistically insignificant.

Figure 3 shows the trend in the walking variable in the treated local authorities and in the control local authorities. We see a similar pre-treatment trend, a clear drop in walking in the treated local authorities in the after period and a bouncing back of 
Table 9: Difference-in-difference estimates of the impact of December 2010 murder of Joanna Yeates on time spent doing physical activity

\begin{tabular}{lcccccc}
\hline \hline & \multicolumn{3}{c}{ Difference-in-difference } & \multicolumn{3}{c}{ Differentially adjusted diff-in-diff } \\
& Estimate & Mean & $\mathrm{N}$ & Estimate & Mean & $\mathrm{N}$ \\
\hline All walking & $-38.0^{* * *}$ & 234 & 28,986 & $-30.6^{*}$ & 235 & 64,937 \\
& $(14.609)$ & & & $(16.408)$ & & \\
Transport walking & 8.9 & 88 & 28,986 & -1.7 & 86 & 64,937 \\
& $(11.307)$ & & & $(9.182)$ & & \\
Leisure walking & $-46.9^{*}$ & 146 & 28,986 & $-28.8^{* *}$ & 149 & 64,937 \\
\multirow{2}{*}{ All activity } & $(24.410)$ & & & $(14.234)$ & & \\
& $-108.3^{* * *}$ & 544 & 28,986 & 11.1 & 548 & 64,937 \\
\hline \hline
\end{tabular}

Robust standard errors in brackets, clustered by local authority. ${ }^{*}$ Significant at $10 \%,{ }^{*}$ significant at $5 \%, * * *$ significant at $1 \%$

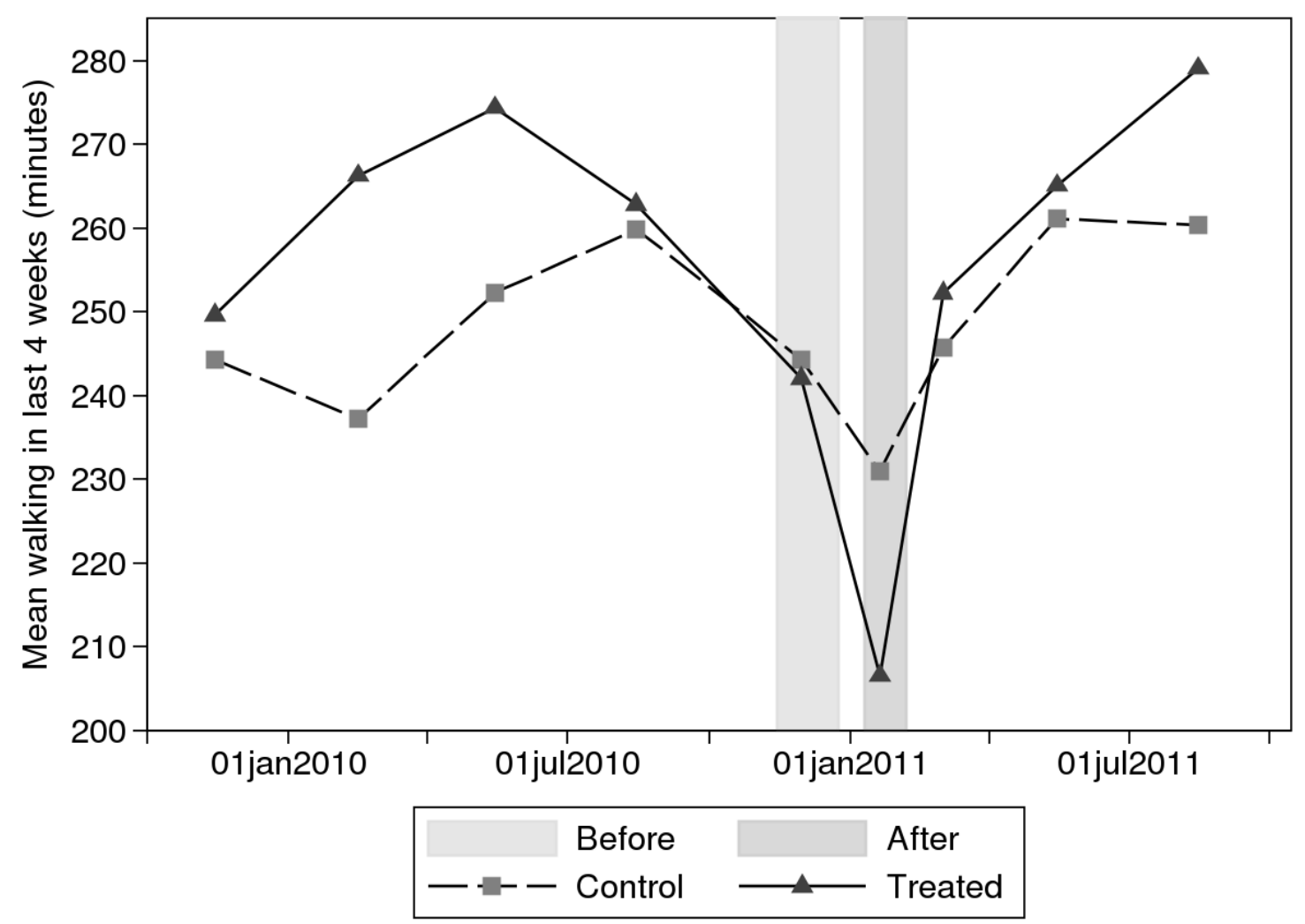

Figure 3: Trends in walking in local authorities affected by murder of Joanna Yeates and in control local authorities 
walking to pre-treatment levels after the murderer is arrested.

Results for the crime shock caused by the disappearance of Claudia Lawrence are in Table 10. Both estimators suggest that Lawrence's disappearance lead to a drop in walking. The d-i-d estimate of -34 minutes is equivalent to a drop of around $15 \%$ at the sample mean while the differentially adjusted difference-in-difference estimate of -59 minutes is equivalent to a $25 \%$ drop. The results for transport walking and leisure walking suggest that the drop in walking caused by Lawrence's disappearance is driven by a drop in transport walking. The $\mathrm{d}$-i-d estimate of -38 minutes, a $45 \%$ drop in transport walking at the mean of 82 minutes, is statistically significant at the $1 \%$ level and similar to the differentially adjusted difference-in-difference estimate of -55 minutes. This pattern of response fits with the belief that Lawrence came to harm on her way to work. The d-i-d estimate and the triple difference estimates for physical activity are similar and indicate that the crime shock resulted in a 12 to $15 \%$ fall in total physical activity. This fall takes the mean individual well below the public health target of 600 minutes of physical activity over the four-week period.

Table 10: Difference-in-difference estimates of the impact of December 2009 disappearance of Claudia Lawrence on time spent doing physical activity

\begin{tabular}{lcccccc}
\hline \hline & \multicolumn{3}{c}{ Difference-in-difference } & \multicolumn{3}{c}{ Differentially adjusted diff-in-diff } \\
& Estimate & Mean & $\mathrm{N}$ & Estimate & Mean & $\mathrm{N}$ \\
\hline All walking & $-34.1^{*}$ & 242 & 34,349 & $-58.8^{*}$ & 243 & 69,203 \\
& $(19.459)$ & & & $(34.650)$ & & \\
Transport walking & $-38.3^{* * *}$ & 82 & 34,349 & $-55.3^{* *}$ & 83 & 69,203 \\
& $(5.550)$ & & & $(25.456)$ & & \\
Leisure walking & 4.1 & 161 & 34,349 & -3.5 & 161 & 69,203 \\
& $(18.089)$ & & & $(31.917)$ & & \\
All activity & -72.7 & 597 & 34,349 & -93.3 & 603 & 69,203 \\
& $(61.543)$ & & & $(126.112)$ & & \\
\hline \hline
\end{tabular}

Robust standard errors in brackets, clustered by local authority. ${ }^{*}$ Significant at $10 \%,{ }^{* *}$ significant at $5 \%, * * *$ significant at $1 \%$

Figure 4 shows the trend in transport walking in the treated areas and the control areas. Again we see a drop in transport walking during the treatment period and a bouncing back to pre-treatment levels after it became clear that the disappearance was not connected to a serial killer and that Lawrence might not have been a random victim. ${ }^{19}$ The vertical lines in Figure 4 indicate the 25 March - the beginning of the treatment period - in the previous and following year. This shows that transport walking normally rose around this time in the treated areas.

\footnotetext{
${ }^{19}$ The lead detective made a statement about Lawrence's relationships having "had an element of complexity and mystery to them" in early June 2009 (Glendinnng 2009).
} 


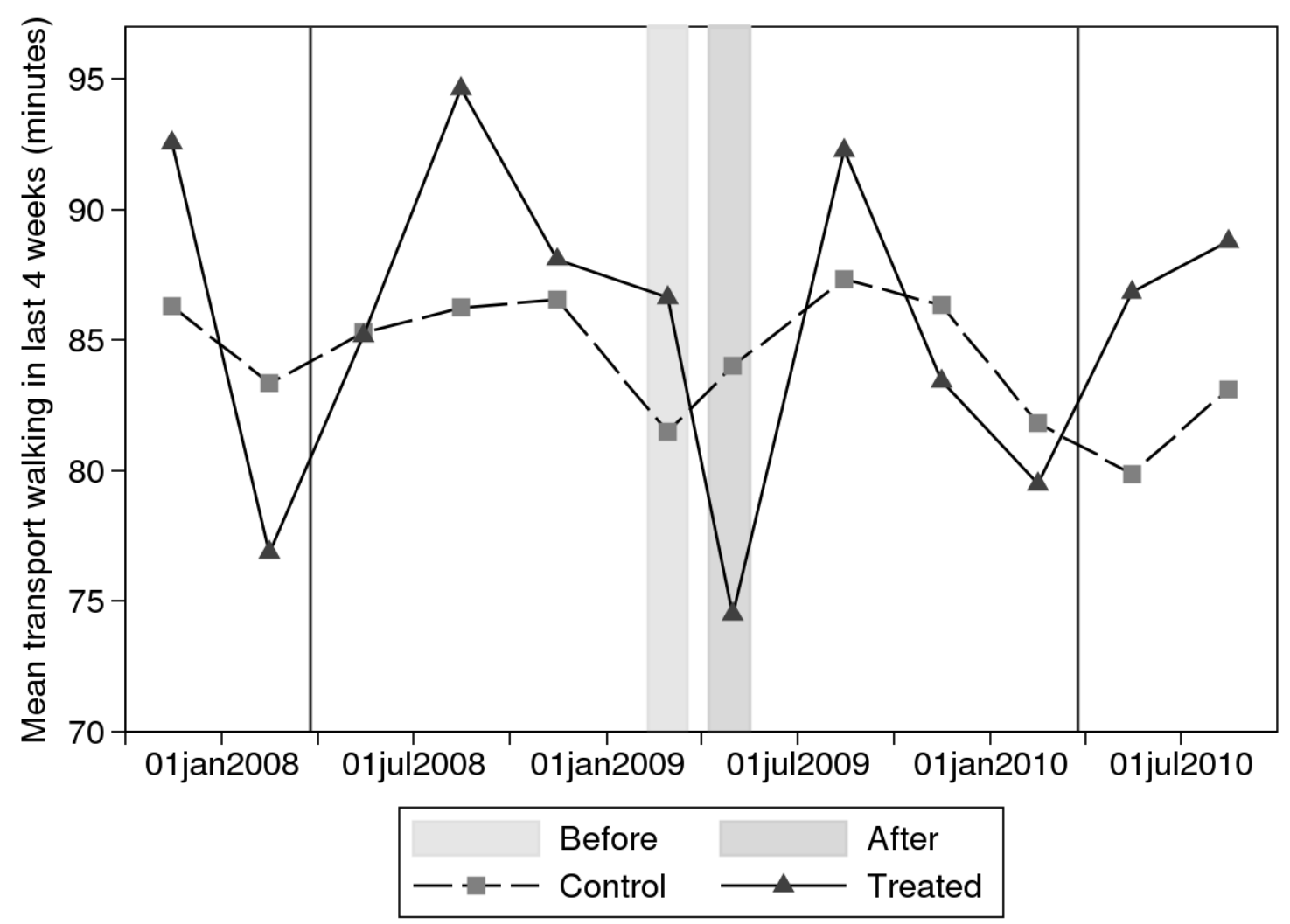

Figure 4: Trends in transport walking in local authorities affected by disappearance of Claudia Lawrence and in control local authorities. Vertical lines indicate 25 March (begin of treatment period) in previous and following year 
The broad similarity of the simple d-i-d and the triple difference estimates supports the validity of our identification strategy. We conclude that these two high-profile crimes led to a drop in walking of between 30 and 60 minutes and a drop in total physical activity of between 70 and 100 minutes. These estimates are 3 to 6 times larger than our estimates in Section 4 for a fall in the local crime rate from the $75^{\text {th }}$ to the $25^{\text {th }}$ percentile. This makes sense. Most individuals experience crime only indirectly and therefore "everyday" changes in local crime rates have a small impact on the perceived probability of becoming a victim of crime while walking. The extensive media coverage of the Joanna Yeates and Claudia Lawrence cases, however, ensured a large impact of these two violent crimes on the perceived probability of becoming a victim of crime in the local areas where the women had been murdered/disappeared.

\section{Welfare implications}

To give some indication of the economic significance of our estimates, we examine the effect of the fall in walking on two health outcomes. The beneficial effects of walking are well established for both coronary heart disease and diabetes (World Health Organization 2002). We therefore calculate by how much an increase in walking following a drop in crime to the $25^{\text {th }}$ percentile of the sample distribution could reduce the number of acute myocardial infarction events (heart attacks) and newly diagnosed cases of Type 2 diabetes.

The bulk of the medical literature reports relative risks for quintiles of the sample distribution of energy usage. ${ }^{20}$ Mirroring this study design, we use the regression model for walking (Column 6 of Table 4) to predict the time spent walking for respondents who report no cycling and no other types of sport and recreational physical activity and determine the quintiles of the predicted walking days distribution. This $53 \%$ of the sample who report walking as the only form of exercise or no exercise at all in the last four weeks are most likely to benefit from increased walking. We then replace the actual violent crime rate with the $25^{\text {th }}$ percentile if it is above the $25^{\text {th }}$ percentile, predict the number of walking days and calculate the number of respondents in each of the quintiles. Table 11 presents the results in the first panel.

We next calculate the number of acute myocardial infarction events we expect to

\footnotetext{
${ }^{20}$ Researchers use a standardized classification of the energy expenditure associated with physical activities to calculate an energy expenditure score in metabolic equivalents (MET score) from responses to questions about frequency and duration of different types of physical activity in a typical week. They then calculate disease risks for each of the five quintiles of the distribution of these MET scores.
} 
Table 11: Estimated number of acute myocardial infarction (AMI) events and new diagnoses of Type 2 diabetes according to quintile of distribution of predicted time spent walking for original violent crime rate and violent crime rate at $25^{\text {th }}$ percentile

\begin{tabular}{|c|c|c|c|c|c|c|}
\hline Quintile & $\overline{1}$ & $\overline{2}$ & 3 & $\overline{4}$ & 5 & Total \\
\hline \multicolumn{7}{|l|}{ Observations in quintile } \\
\hline Original crime rate & 101,702 & 101,704 & 101,703 & 101,703 & 101,702 & 508,514 \\
\hline $25^{\text {th }}$ percentile & 90,906 & 86,715 & 96,298 & 108,503 & 126,092 & 508,514 \\
\hline $\begin{array}{l}\text { Incidence of AMI } \\
\text { (per 100,000 pop.) }\end{array}$ & $80 \times 1$ & $80 \times 0.91$ & $80 \times 0.82$ & $80 \times 0.75$ & $80 \times 0.68$ & \\
\hline Original crime rate & 81 & 74 & 67 & 61 & 55 & 338 \\
\hline $25^{\text {th }}$ percentile & 73 & 63 & 63 & 65 & 69 & 333 \\
\hline Difference & & & & & & 5 \\
\hline \multicolumn{7}{|c|}{ Incidence of Type 2 diabetes } \\
\hline \multicolumn{7}{|c|}{ New diabetes diagnoses in quintile } \\
\hline Original crime rate & 438 & 416 & 351 & 355 & 324 & 1,884 \\
\hline $25^{\text {th }}$ percentile & 392 & 355 & 332 & 379 & 402 & 1,860 \\
\hline Difference & & & & & & 24 \\
\hline
\end{tabular}

happen in each of the quintiles for the original level of violent crime and for violent crime at the $25^{\text {th }}$ percentile. We use a basic incidence rate of 80 per 100,000 population ${ }^{21}$ and the multivariate relative risks according to quintiles of walking in Manson et al. (2002). These results are in the second panel of Table 11. Results in the third panel are for new diagnoses of Type 2 diabetes using a basic incidence rate of 431 per 100,000 population (González et al. 2009) and the multivariate adjusted (including BMI) relative risks according to quintiles of walking from Hu et al. (1999).

The results show that a reduction in the violent crime rate to the $25^{\text {th }}$ percentile could have reduced acute myocardial infarction events from 338 to 333 and new Type 2 diabetes diagnoses from 1,884 to 1,860. Under the assumption that the proportion of the English population who do not do any exercise other than walking or do not do any exercise at all is given by our sample mean (53\%), there are around 20.6 million people in the age range 15-74 years who could potentially benefit. This is 40 times the number in our sample (508,514 person-years) and therefore the total number of acute myocardial infarction events that could be prevented is $200(=40 \times 5)$ and the total number of new Type 2 diabetes diagnoses that could be prevented is $960(=40 \times 24)$.

To put a monetary value on these numbers we take a lower bound and calculate

\footnotetext{
${ }^{21} 80$ is the mean of the rates for men and women under 75 for the period 2005 to 2010 reported in British Heart Foundation (2012).
} 
only the direct costs to the NHS. The cost per hospital admission for acute myocardial infarction without complications is $£ 2,037$ and $£ 3,029$ with complications. ${ }^{22}$ From NHS discharge data (Hospital Episode Statistics) the proportion of cases with complications has a mean of $25 \%$ over our sample period. Thus the potential savings from reducing acute myocardial infarction events by 200 are $£ 0.46$ million $(150 \times £ 2,037+50 \times$ $£ 3,029$ ). For Type 2 diabetes, Kanavos et al. (2012) estimate the annual direct cost (drugs, inpatient and outpatient care) per patient in 2010 as £3,717. Therefore, 960 fewer cases could save £3.6 million annually. Assuming patients are diagnosed at age 50 and live until age 70, the total savings could be $£ 72$ million (20 years $\times £ 3.6$ million).

These estimates are a lower bound of the welfare implications of violent crime through its effect on walking. Additional benefits of reducing crime include reductions in traffic congestion, road danger and noise (Sinnett et al. 2011) as well as air pollution and its impact on health (Janke et al. 2009). Walking also promotes mental health and provides opportunities for social interactions, which supports the development of social capital (Sinnett et al. 2011).

\section{Conclusion}

We contribute to the literature on the wider consequences of crime in society by providing evidence on the causal effect of local area violent crime on adults' participation in physical activity. We focus on walking as it is the most common form of physical activity, contributes to individual health and through individuals' interactions with people in their neighbourhood may contribute to neighbourhood quality. To provide causal evidence, we use a sample of nearly one million people residing in over 320 local authority areas across England over 22 quarters and back up this analysis with evidence from the crime shocks caused by the murder of Joanna Yeates in Bristol in December 2010 and the disappearence of Claudia Lawrence in York in March 2009.

An increase in local area violent crime leads to a statistically significant reduction in the time spent walking at a steady average pace or faster continuously for at least 30 minutes over a four-week period. The effect of reducing crime from the $75^{\text {th }}$ to the $25^{\text {th }}$ percentile of the sample distribution is of roughly the same magnitude as increasing the average daily minimum temperature over the four-week period by $7{ }^{\circ} \mathrm{C}$ or as reducing average daily rainfall over the four-week period by $8 \mathrm{~mm}$. The effect works mainly through reducing transport walking, rather than walking undertaken for leisure or recreational purposes, although a caveat applies as the split into transport

\footnotetext{
${ }^{22}$ Payment by Results tariff 2005/2006 (Department of Health 2004)
} 
and leisure walking is potentially measured with error. The estimated drop in walking tranlates into a drop in the total time spent doing physical activity. The two highprofile cases of Joanna Yeates and Claudia Lawrence have a larger impact, as might be expected given the extensive media attention.

In terms of economic significance, our estimates suggest that following a reduction in crime to the $25^{\text {th }}$ percentile of the sample distribution the predicted increase in walking among adults for whom walking is the only form of exercise or who do not do any exercise at all could potentially save the NHS £4.1 million per annum from reductions in heart attacks and new diagnoses of Type 2 diabetes. These estimates ignore gains for car drivers and the urban environment from falls in traffic congestion and the health benefits from reductions in traffic-generated air pollution.

Overall, the evidence points to a negative effect of violent crime on the wider community through the mechanism of increased concern about personal security. Our research adds to recent studies that identify causal effects of violent crime on daily activity and mental wellbeing of non-victims and suggests that policies that reduce the amount of violent crime in society have positive effects well beyond the direct effects of fewer victims of crime. 


\section{Appendix A Data description}

The Active People Survey (APS) is commissioned by Sport England. Interviews are spread evenly across the 12 months of each survey period and are conducted by telephone using Random Digit Dialling. The CATI system randomly selects one person aged 16 or over from the eligible household members. The average response rate is $25 \%$. Various piloting stages ensure quality data.

We use the first five waves of the APS: APS1 (October 2005 to October 2006), APS2 (2007 to 2008), APS3 (2008 to 2009), APS4 (2009 to 2010) and APS5 (2010 to 2011). APS1, $\mathrm{n}=363,724 ;$ APS2, $\mathrm{n}=191,325 ;$ APS3, $\mathrm{n}=193,947 ;$ APS4, $\mathrm{n}=$ 188,354 and APS5, $\mathrm{n}=166,805$. APS5 differed to APS1-4 in that certain questions about socio-economic status are randomly asked of only $50 \%$ of the sample, including household income and car ownership.

At the beginning of the interview, respondents are asked "I would like you to think about all the walking you have done. Please include any country walks, walking to and from work or the shops and any other walks you may have done. Please exclude time spent walking around shops. In the last four weeks, that is since ... have you done at least one continuous walk lasting at least 5 minutes?" This question also identifies individuals who are unable to walk (1.4\% of respondents). Next, the interviewer asks: "In the last four weeks, that is since ... have you done at least one continuous walk lasting at least 30 minutes?" followed by "On how many days in the last four weeks have you walked for at least 30 minutes?". The next question is "How would you describe your usual walking pace?" with the answer options being "a slow pace", "a steady average pace", "a fairly brisk pace" and "a fast pace". If the respondent selects at least "a steady average pace" we use the reported number of walking days to construct our walking measure. 
Table A-1: Data sources

\begin{tabular}{|c|c|c|}
\hline Variables & Source of data & $\begin{array}{l}\text { Time periods cov- } \\
\text { ered }\end{array}$ \\
\hline $\begin{array}{l}\text { Physical activity measures } \\
\text { and individual-level con- } \\
\text { trols }\end{array}$ & Active People Survey 1-5 & $\begin{array}{l}\text { Oct 2005-Oct 2006, } \\
\text { Oct 2007-Oct } 2011\end{array}$ \\
\hline Police recorded crime & $\begin{array}{l}\text { Freedom of Information request } \\
\text { to UK Home Office }\end{array}$ & II/2004-III/2011 \\
\hline Local authority population & $\begin{array}{l}\text { Mid-year population estimates } \\
\text { from Office for National Statistics }\end{array}$ & 2004-2010 \\
\hline Unemployment rate & $\begin{array}{l}\text { Model-based estimates of lo- } \\
\text { cal authority unemployment for } \\
\text { one year periods from Nomis } \\
\text { (www.nomisweb.co.uk) }\end{array}$ & $\begin{array}{l}\text { Oct 2004/Sep 2005- } \\
\text { Oct 2010/Sep } 2011\end{array}$ \\
\hline Weather & $\begin{array}{l}\text { Met Office - MIDAS Land Sur- } \\
\text { face Stations data }\end{array}$ & Sep 2005-Oct 2011 \\
\hline Perception of crime & $\begin{array}{l}\text { British Crime Survey 2005-06, } \\
2006-07,2007-08\end{array}$ & II/2005-I/2008 \\
\hline
\end{tabular}


Table A-2: Descriptive statistics of individual-level controls

\begin{tabular}{|c|c|c|c|}
\hline Variable & Mean & & \\
\hline Male & 0.41 & & \\
\hline Age 16 to 24 & 0.09 & & \\
\hline Age 25 to 34 & 0.14 & & \\
\hline Age 35 to 44 & 0.21 & Variable & Mean \\
\hline Age 45 to 54 & 0.20 & Single adult & 0.32 \\
\hline Age 55 to 64 & 0.21 & Family status missing & 0.03 \\
\hline Age 65 to 74 & 0.16 & Child aged 0 to 4 & 0.11 \\
\hline White British & 0.89 & Child aged 5 to 10 & 0.16 \\
\hline Indian & 0.02 & Child aged 11 to 15 & 0.14 \\
\hline Pakistani & 0.01 & Child age missing & 0.00 \\
\hline Bangladeshi & 0.00 & $<£ 10,400$ per annum & 0.09 \\
\hline Caribbean & 0.01 & $£ 10,400$ to $£ 20,700$ & 0.17 \\
\hline African & 0.01 & $£ 20,800$ to $£ 31,199$ & 0.15 \\
\hline Chinese & 0.00 & $£ 31,200$ to $£ 41,599$ & 0.11 \\
\hline Other ethnic group & 0.06 & $£ 41,600$ to $£ 51,999$ & 0.08 \\
\hline No qualifications & 0.13 & $£ 52,000$ or more & 0.12 \\
\hline Other & 0.03 & Household income missing & 0.29 \\
\hline O level & 0.23 & Social rented housing & 0.11 \\
\hline A level & 0.16 & Housing missing & 0.03 \\
\hline Higher (less than degree) & 0.10 & Car in household & 0.78 \\
\hline Degree or higher & 0.30 & Car missing & 0.08 \\
\hline Qualification missing & 0.05 & APS5 - missing questions & 0.08 \\
\hline Working full-time & 0.44 & Monday & 0.16 \\
\hline Working part-time & 0.16 & Tuesday & 0.17 \\
\hline Unemployed $<12$ months & 0.02 & Wednesday & 0.17 \\
\hline Unemployed $>12$ months & 0.03 & Thursday & 0.16 \\
\hline Retired & 0.21 & Friday & 0.13 \\
\hline Non-participant (home/child) & 0.05 & Saturday & 0.12 \\
\hline Non-participant (disabled) & 0.02 & Sunday & 0.09 \\
\hline Student & 0.04 & Observations & 964,318 \\
\hline Other & 0.01 & & \\
\hline Employment status missing & 0.02 & & \\
\hline Chronic limiting condition & 0.15 & & \\
\hline Limiting condition missing & 0.02 & & \\
\hline
\end{tabular}


Table A-3: Descriptive statistics of British Crime Survey data

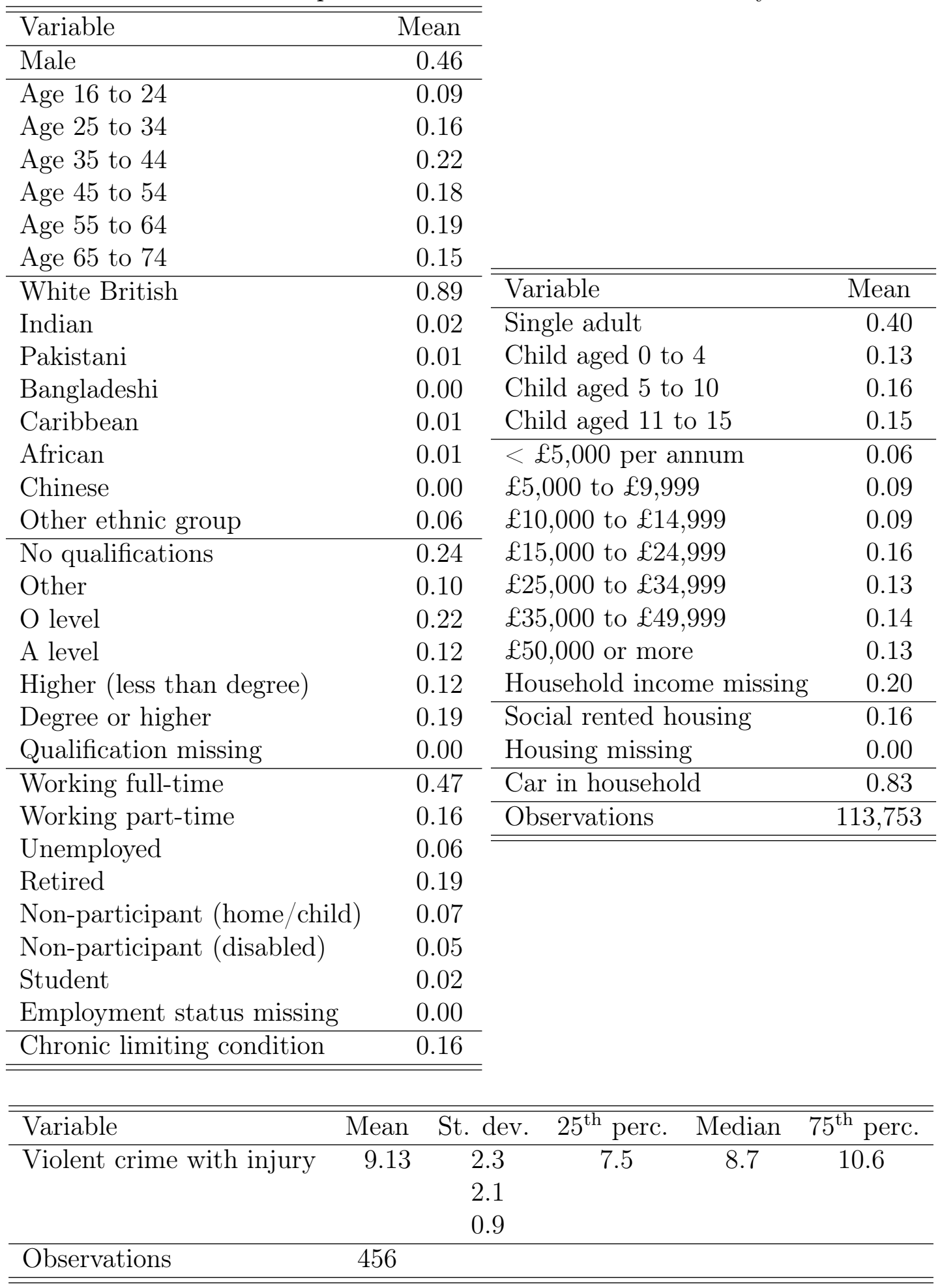



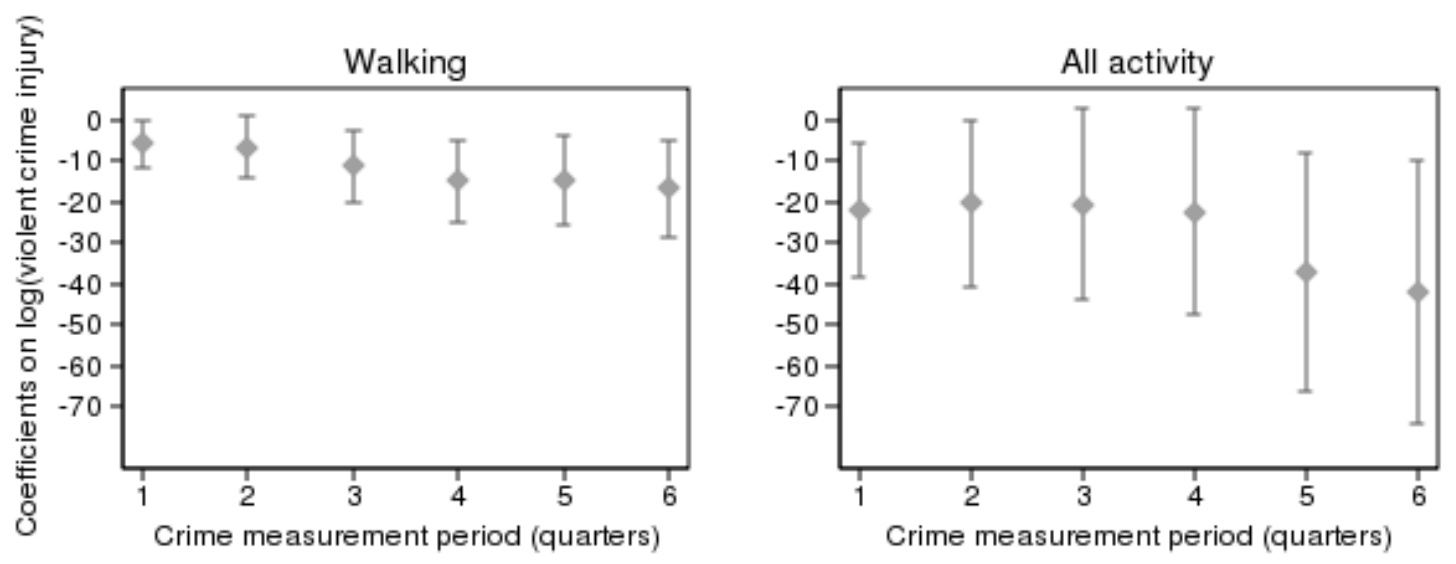

Figure B-1: Estimates for different measurement periods for crime variable: Coefficients on $\log$ (violent crime injury) and $95 \%$ confidence intervals

\section{Appendix B Additional robustness checks}

We examine the robustness of our results to changes in the crime measurement period. Next we show that results from a nonlinear model that accounts for the lumpiness in the distribution of our main outcome variables are in line with our main results and indicate that violent crime affects physical activity at the extensive as well as intensive margin.

\section{Appendix B.1 Crime measurement period}

Our measure of crime is the sum of the quarterly rates in the four quarters preceding the interview quarter. To explore the sensitivity of our results to different definitions of the crime measurement period, Figure B-1 reports the crime coefficients and $95 \%$ confidences intervals from six different regressions. The first regression uses only the crime rate in the quarter preceding the interview, the second regression the sum of the crime rates in the two quarters preceding the interview and so on, with the sixth regression using the sum of the crime rates in the six quarters preceding the interview. To make coefficients comparable, we annualise the crime measures, i.e. we multiply the one-quarter measure by 4 , the two-quarter measure by 2 , the three-quarter measure by $4 / 3$ and so on.

For both walking and all physical activity, the figure shows an increasing deterrent effect of crime as the period over which crime is measured is extended. The small effect of the more recent crime rate may be picking up the fact that respondents update their beliefs about local crime rates only slowly. But it may also reflect measurement error 
from using a short time window. While the effect of crime is largest at 6 quarters (perhaps supporting the measurement error interpretation), the confidence intervals indicate there is little difference between crime measured over 4 quarters and crime measured over 6 . We therefore conclude our results are reasonably robust to the precise number of quarters used to define the crime rate.

\section{Appendix B.2 The distribution of the outcome variables}

The distribution of our dependent variables has peaks at various days, reflecting patterns in transport and leisure walking and other types of physical activity. For 32\% of respondents our walking measure is zero minutes. There are spikes at 120, 240 and 360 minutes which correspond to walking once, twice or three times a week, respectively. A spike at 600 minutes corresponds to walking on 20 days and a smaller spike at 300 minutes to walking on 10 days, reflecting the 5 weekdays in each of the four weeks of the measurement period. For $13 \%$ of respondents our walking measure is 840 minutes, i.e. walking every day continuously for at least thirty minutes over the measurement period of 28 days. A similar pattern emerges for all physical activity: $21 \%$ of respondents report no physical activity at all while $30 \%$ of respondents report physical activity ranging from 840 minutes to 15,120 minutes.

Table B-1: Multinomial logit models of time spent doing physical activity in last four weeks: Coefficients on $\log$ (violent crime with injury)

\begin{tabular}{lclc}
\hline \hline Categories & Walking & Categories & All activity \\
\hline 0 minutes & Base outcome & 0 minutes & Base outcome \\
1 to 120 minutes & 0.005 & 1 to 360 minutes & -0.007 \\
& $(0.044)$ & & $(0.046)$ \\
121 to 420 minutes & -0.019 & 361 to 840 minutes & $-0.105^{* *}$ \\
& $(0.051)$ & & $(0.048)$ \\
$>420$ minutes & $-0.131^{* * *}$ & $>840$ minutes & -0.057 \\
& $(0.048)$ & & $(0.049)$ \\
\hline \hline
\end{tabular}

Robust standard errors in brackets, clustered by local authority. All models include local authority effects, year-quarter effects and local authority-specific trends as well as controls for all other crime, unemployment, rainfall, daily maximum and minimum temperature and individual-level controls for gender, age, ethnicity, highest educational attainment, employment status, an indicator for a limiting long-standing illness or disability, family structure, household income, an indicator for living in social rented housing and an indicator for car in household. 964,318 observations in 323 local authorities in all models. ${ }^{*}$ Significant at $10 \%, * *$ significant at $5 \%,{ }^{* * *}$ significant at $1 \%$

To check the robustness of our linear specification, we estimate a multinomial logit model with four categories: 0 minutes, 1 to 120 minutes, 121 to 420 minutes and more 
than 420 minutes for walking and 0 minutes, 1 to 360 minutes, 361 to 840 minutes and more than 840 minutes for all physical activity. Each of these categories accounts for approximately one-quarter of the observations. We include the same controls as in our main specification. The results are in Table B-1.

For walking, the negative and statistically significant crime coefficient of -0.131 in the $>420$ minutes equation suggests that as crime increases the probability of walking for more than 420 minutes rather than 0 minutes decreases. The coefficient for the $>420$ minutes versus 1 to 120 minutes contrast is of similar size $(-0.131-0.005=$ $-0.136)$ as is the coefficient for the $>420$ minutes versus 121 to 420 minutes contrast $(-0.131--0.019=-0.112)$, suggesting that an increase in crime also reduces the probability of walking for more than 420 minutes rather than 1 to 120 minutes or 121 to 420 minutes. Thus, crime seems to affect walking at extensive as well as the intensive margin as these results suggest that an increase in crime induces individuals who walk regularly to stop walking altogether or to reduce the amount of walking.

The results for all physical activity are similar. The crime coefficient in the 361 to 840 minutes equations is negative and statistically significant, indicating that a crime increase reduces the probability of spending 361 to 840 minutes doing physical activity instead of doing no physical activity at all. The coefficient for the 361 to 840 minutes versus 1 to 360 minutes contrast is of similar size $(-0.105--0.007=-0.098)$. Again, crime seems to affect physical activity at the extensive as well as the intensive margin. Individuals who exercise regularly for 361 to 840 minutes stop exercising altogether or reduce the amount of exercise to below the target of 600 minutes. Overall, the results of the multinomial logit model are in line with the linear model's finding of a negative effect of crime on physical activity. 


\section{References}

Audrey, S., Procter, S. and Cooper, A.: 2014, The contribution of walking to work to adult physical activity levels: a cross sectional study, International Journal of Behavioral Nutrition and Physical Activity 11(1), 37.

Barkham, P.: 2009, Ten days of helplessness, The Guardian (28 March 2009).

URL: http: // www. theguardian. com/uk/2009/mar/28/missing-peopleclaudia-lawrence

Bassett, D. R., Pucher, J., Buehler, R., Thompson, D. L. and Crouter, S. E.: 2008, Walking, cycling, and obesity rates in europe, north america, and australia, Journal of Physical Activity and Health 5(6), 795-814.

Bell, B., Blundell, R. and Reenen, J. V.: 1999, Getting the unemployed back to work: The role of targeted wage subsidies, International Tax and Public Finance 6, 339 360 .

Braakmann, N.: 2012, How do individuals deal with victimization and victimization risk? longitudinal evidence from mexico, Journal of Economic Behaviour 85 Organization 84(1), 335-344.

British Heart Foundation: 2012, Coronary heart diseases statistics. A compendium of health statistics. 2012 edition, British Heart Foundation.

Chermak, S. M.: 1994, Body count news: How crime is presented in the news media, Justice Quarterly 11(4), 561-582.

Cohn, E. G.: 1990, Weather and crime, British Journal of Criminology 30(1), 51-64.

Coleman, C. and Moynihan, J.: 1996, Understanding crime data - Haunted by the dark figure, Crime and Justice, Open University Press.

Cornaglia, F., Feldman, N. E. and Leigh, A.: 2014, Crime and mental well-being, Journal of Human Resources 49(1), 110-140.

Cornaglia, F. and Leigh, A.: 2011, Crime and mental wellbeing, CEP Discussion Paper 1049, Centre for Economic Performance.

Cullen, J. B. and Levitt, S. D.: 1999, Crime, urban flight, and the consequences for cities, The Review of Economics and Statistics 81, 159-169.

Department of Health: 2004, National Tariff 2005-06, Department of Health.

du Toit, L., Cerin, E., Leslie, E. and Owen, N.: 2007, Does walking in the neighbourhood enhance local sociability?, Urban Studies 44(9), 1677-1695.

Duffy, B., Wake, R., Burrows, T. and Bremner, P.: 2008, Closing the gaps - crime and public perception, International Review of Law Computers 86 Technology 22(12), 17-44. 
Dustmann, C. and Fasani, F.: 2013, The effect of local area crime on mental health, IZA Discussion Paper 7711, IZA: Forschungsinstitut zur Zukunft der Arbeit.

Ellen, I. G. and O'Regan, K. M.: 2010, Crime and urban flight revisited: The effect of the 1990s drop in crime on cities, Journal of Urban Economics 68(3), 247-259.

Foster, S. and Giles-Corti, B.: 2008, The built environment, neighborhood crime and constrained physical activity: An exploration of inconsistent findings, Preventive Medicine 47, 241-251.

Gibbons, S.: 2004, The costs of urban property crime, The Economic Journal 114(499), F441-F463.

Glendinnng, L.: 2009, Missing chef Claudia Lawrence had 'mystery' relationships, The Guardian (3 June 2009).

URL: $\quad h t t p: / / w w w . ~ t h e g u a r d i a n . c o m / u k / 2009 / j u n / 03 / c l a u d i a-$ lawrence-mystery-relationships

González, E. L. M., Johansson, S., Wallander, M.-A. and Rodríguez, L. A. G.: 2009, Trends in the prevalence and incidence of diabetes in the UK: 1996-2005, Vol. 63.

Greenbaum, R. T. and Tita, G. E.: 2004, The impact of violence surges on neighbourhood business activity, Urban Studies 41(13), 2495-2514.

Greer, C.: 2007, News media, victims and crime, in P. Davies, P. Francis and C. Greer (eds), Victims, Crime and Society, Sage Publications Ltd., London, chapter 2, pp. 20-49.

Grossman, M.: 2006, Education and nonmarket outcomes, in E. A. Hanushek and F. Welch (eds), Handbook of the Economics of Education, Volume I, NorthHolland, pp. 577-633.

Hamermesh, D. S.: 1999, Crime and the timing of work, Journal of Urban Economics 45, 311-330.

Hansen, C. B.: 2007, Generalized least squares inference in panel and multilevel models with serial correlation and fixed effects, Journal of Econometrics 140(2), 670-694.

Hipp, J. R.: 2010, Resident perceptions of crime and disorder: How much is "bias" and how much is social environment differences?, Criminology 48(2), 475-508.

Home Office: 2010, Public perceptions of policing, engagement with the police and victimisation: Findings from the 2009/10 British Crime Survey, Home Office.

Home Office: 2011, Crime in England and Wales 2010/11 - Findings from the British Crime Survey and police recorded crime (2nd Edition), Home Office.

Hu, F. B., Sigal, R. J., Rich-Edwards, J. W., Colditz, G. A., Willett, W. C., Speizer, F. E. and Manson, J. E.: 1999, Walking compared with vigorous physical activity and risk of Type 2 diabetes in women, Journal of the American Medical Association 282(15), 1433-1439. 
Jacob, B., Lefgren, L. and Moretti, E.: 2007, The dynamics of criminal behavior: Evidence from weather shocks, The Journal of Human Resources 42(3), 489-527.

Janke, K., Propper, C. and Henderson, J.: 2009, Do current levels of air pollution kill? The impact of air pollution on population mortality in england, Health Economics 18(9), 1031-1055.

Johnston, L.: 2006, Diversifying police recruitment? the deployment of police community support officers in london, The Howard Journal of Criminal Justice 45(4), 388-402.

Kanavos, P., van den Aardweg, S. and Schurer, W.: 2012, Diabetes expenditure, burden of disease and management in 5 eu countries, Technical report, LSE Health, London School of Economics.

Kling, J. R., Liebman, J. B. and Katz, L. F.: 2001, Bullets don't got no name: Consequences of fear in the ghetto, JCPR Working Paper 225, Northwestern University/University of Chicago Joint Center for Poverty Research.

Lindström, M.: 2008, Means of transportation to work and overweight and obesity: A population-based study in southern sweden, Preventive Medicine 46(1), 22-28.

Manson, J. E., Greenland, P., LaCroix, A. Z., Stefanick, M. L., Mouton, C. P., Oberman, A., Perri, M. G., Sheps, D. S., Pettinger, M. B. and Siscovick, D. S.: 2002, Walking compared with vigorous exercise for the prevention of cardiovascular events in women, The New England Journal of Medicine 347(10), 716-725.

Messer, L. C., Kaufman, J. S., Dole, N., Herring, A. and Laraia, B. A.: 2006, Violent crime exposure classification and adverse birth outcomes: a geographically-defined cohort study, Internationa Journal of Health Geographics $\mathbf{5}$.

Metcalfe, R., Powdthavee, N. and Dolan, P.: 2011, Destruction and distress: Using a quasi-experiment to show the effects of the september 11 attacks on mental well-being in the united kingdom, The Economic Journal 121(550), F81-F103.

Morris, S.: 2011a, Joanna Yeates murder: the full truth may never be known, The Guardian (28 October 2011).

URL: http://www. theguardian. com/uk/2011/oct/28/ joanna-yeatescase-vincent-tabak

Morris, S.: 2011b, Joanna Yeates: police warn public to be watchful while killer remains at large, The Guardian (2 January 2011).

URL: http://www. theguardian. com/uk/2011/jan/02/joanna-yeatespolice-safety-warning

NICE: 2012, Walking and cycling: local measures to promote walking and cycling as forms of travel or recreation, National Institute for Health and Care Excellence, Manchester.

Rosenthal, S. S. and Ross, A.: 2010, Violent crime, entrepeneurship, and cities, Journal of Urban Economics 67(1), 135-149. 
Rubin, G. J., Brewin, C. R., Greenberg, N., Simpson, J. and Wessely, S.: 2005, Psychological and behavioural reactions to the bombings in London on 7 july 2005: cross sectional survey of a representative sample of Londoners, British Medical Journal 331(606).

Sinnett, D., Williams, K., Chatterjee, K. and Cavill, N.: 2011, Making the case for investment in the walking environment: a review of the evidence, Living Streets, London.

Sundquist, K., Theobald, H., Yang, M., Li, X., Johansonn, S.-E. and Sundquist, J.: 2006, Neighborhood violent crime and unemployment increase the risk of coronary heart disease: A multilevel study in an urban setting, Social Science $\mathscr{E}$ Medicine 62, 2061-2071.

Sustrans: 2006, Shoppers and how they travel. Information Sheet LN02, Sustrans, Bristol.

U.S. Department of Health and Human Services: 1996, Physical activity and health: a report of the Surgeon General, U.S. Department of Health and Human Services, Atlanta (GA).

Williams, P. and Dickinson, J.: 1993, Fear of crime: Read all about it? - the relationship between newspaper crime reporting and fear of crime, British Journal of Criminology 33(1), 33-56.

World Health Organization: 2002, The World Health Report 2002 - Reducing Risks, Promoting Healthy Life, World Health Organization, Geneva. 